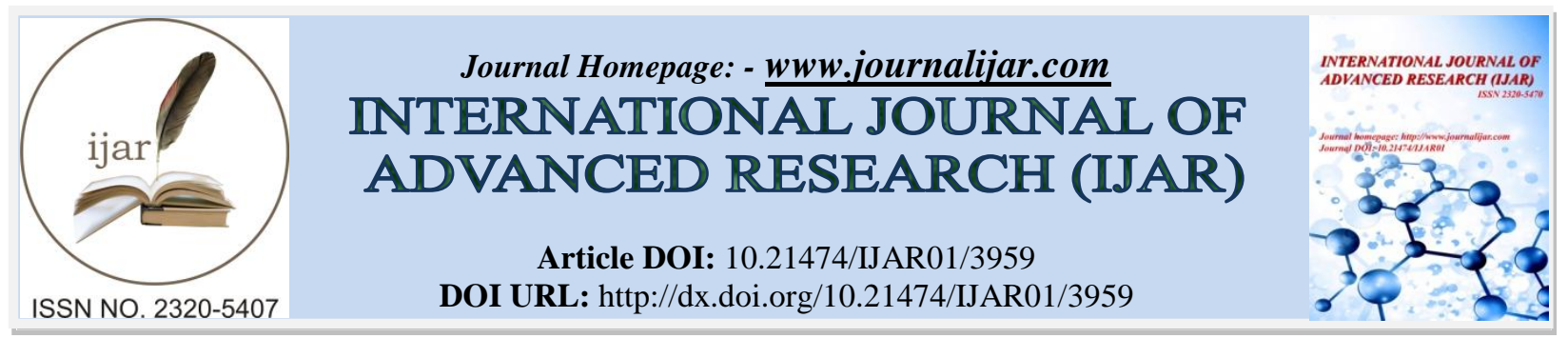

RESEARCH ARTICLE

\title{
Cu AND Mn COMPLEXES OF NICOTINIC ACID AND IMIDAZOLE: A CURRENT REVIEW.
}

\author{
"Shakeel Ahmad Khan', Sadia Kanwal', Ahsan Iqbal ${ }^{3}$ and Waqar Ahmad". \\ 1. Department of Chemistry, University of Management and Technology Lahore-54000, Pakistan. \\ 2. Department of Biochemistry, University of Agriculture Faislabad-38000, Pakistan. \\ 3. Department of Chemistry, GC University, Faisalabad-38000, Pakistan.
}

\section{Manuscript Info}

\section{Manuscript History}

Received: 19 February 2017

Final Accepted: 14 March 2017

Published: April 2017

Key words:-

Synthesis, Pharmacological, Metal,
Complexes, Nicotinic Acid, Imidazole

\begin{abstract}
The copper(II) and Mn(II) complexes with nicotinic acid and imidazole ligands have potentially donor and acceptor character in the formation of a coordination bond and a hydrogen bond. They can function as a ligand-complex or as a self-complementary building block for the construction of the assembly structure due to the formation of a coordination bond or a hydrogen bond. In such self-complementary complexes, the monomer is stabilized as a protonated species under acidic conditions, while under appropriate basic conditions the generated imidazolate nitrogen atom coordinates to the $\mathrm{Cu}$ (II) and $\mathrm{Mn}(\mathrm{II})$ ion of the adjacent unit or hydrogen-bonds to the imidazole as well as nicotinic acid group of the adjacent unit to give assembly structures in the crystals, depending on the ligand framework and the preferred coordination number of the $\mathrm{Cu}(\mathrm{II})$ and $\mathrm{Mn}$ (II) ion. Numerous methods for the synthesis of imidazole and nicotinic acid complexes of $\mathrm{Cu}(\mathrm{II})$ and $\mathrm{Mn}(\mathrm{II})$ also their various structure reactions offer enormous scope in the field of medicine chemistry.
\end{abstract}

Copy Right, IJAR, 2017,. All rights reserved.

\section{Introduction:-}

Copper is metal atom with atomic number 29 and its symbol is $\mathrm{Cu}$. It is ductile having high electrical and thermal conductivity. Copper is found naturally as native $\mathrm{Cu}$. Copper shows $\mathrm{Cu}^{+1}$ and $\mathrm{Cu}^{+2}$ oxidation states and sometimes also shows $\mathrm{Cu}^{+3}$ oxidation state. $\mathrm{Cu}^{+1}$ are diamagnetic and are colorless. $\mathrm{Cu}^{+1}$ is stable mostly in solid form and $\mathrm{Cu}^{+2}$ in aqueous solutions [1]. Due to its properties it is used in many alloys like Brass, Bronze etc. name of copper is derived from Cyprus or cuprum, a place of mining. Copper and its salts are used for decorative and ornamental purposes. It is essential for all organisms. It is part of blood pigment called hemocyanin in mollusks and crustacea but in other organisms like fish and other vertebrates $\mathrm{Cu}$ is replaced by $\mathrm{Fe}$. In humans, copper is present in liver, muscles and bones [2]. Copper is also used as fungicides in agriculture. It has anti biofouling and antimicrobial applications. Copper is biostatic because bacteria's do not grow on it. It destroys bacteria's, viruses and fungi. Copper bracelets are used to cure arthritis symptoms [3].

Manganese is metal atom with symbol Mn and its atomic number is 25 . It occurs as combined form in nature. It is paramagnetic in nature. It rusts like iron and easy to oxidize [4]. Its name is derived from the place of its origin. Their oxidations states that are mostly shown are $\mathrm{Mn}^{+3}$ and $\mathrm{Mn}^{+5}$. Complexes of $\mathrm{Mn}$ (II) show geometry of octahedral [5]. It has many ores. It has wide applications. Many compounds of $\mathrm{Mn}$ are used as pigments to color ceramics and glass. Mn is necessary metal for humans. It is important for development and metabolism. It is part of

Corresponding Author:- Shakeel Ahmad Khan.

Address:- Department of Chemistry, University of Management and Technology Lahore-54000, 
many enzymes like oxidoreductase, transferases, hydrolases, isomerases etc. Mn in excess causes problem. It leads to the condition called as neurodegenerative disorder and it may cause death [6]. Daily intake of Mn with food is 2.3 mg per day for males and less for females. Most of Mn is stored in bones and left of it in liver, kidney and soft tissues of body. During photosynthesis, it also play important role in chloroplast of plants. Fatal dose of Mn is $10 \mathrm{~g}$. It affects cognitive and motor skills. It also effect mucus membrane by necrosis, kidney, liver etc. Weakness, slow speech, rigidity, expression less face etc. are all symptoms to increased level of $\mathrm{Mn}$ in body [7]. Imidazole is an organic compound having molecular formula $\mathrm{C}_{3} \mathrm{H}_{4} \mathrm{~N}_{2}$ and melting point $89-91{ }^{\circ} \mathrm{C}$. It is colorless solid and polar compound with protons on the either sides of two $\mathrm{N}$ - atoms. It has six $\pi$-electrons show resonance and is amphoteric. Imidazole is important component of many natural products and pharmacological molecules. Its ring acts as good ligand with transition metal atoms and performs number of biological functions like inhibiting growth of tumor [8]. It is used for the treatment of fungal infections and present in fungicides, antifungal, antiprotozoal, anticancer, antibacterial, anti-inflammatory and antihypertensive medicines. It combats leukemia by interaction with DNA [9].

Nicotinic acid is an organic compound also known as vitamin $\mathbf{B}_{3}$. It is colorless, water soluble solid having molecular formula $\mathrm{C}_{6} \mathrm{H}_{5} \mathrm{NO}_{2}$ and melting point $237^{\circ} \mathrm{C}$. It is derivative of pyridine with carboxyl group at 3position.Insufficient Nicotinic acid cause diseases like anemia, headache, tiredness, nausea, skin infection. Its chronic deficiency causes pellagra. Nicotinic acid is useful in minimizing the chances of cardiovascular diseases [10]. Niacin is found in many foods i.e. chicken, beef, fish, peanuts. High dose of Niacin cause toxic effect like maculopathy (thickening of retina) which causes blindness [11]. It also causes elevation of blood sugar, Diabetes mellitus [12].

\section{Metal Complexes of Nicotinic Acid and Imidazole:- $\mathrm{Cu}^{+2}$ Complexes with Nicotinic acid:-}

It was stated that complexes of mixed ligand nicotinic acid with other carboxylic acids were synthesized. Studies showed that nicotinic acid or vitamin $\mathrm{B}_{3}$ was used as physiological and anti-hyper lipidemic functions. $\mathrm{Cu}$ complexes were tested and observed antimicrobial activity against Bacillus subtilis with $256 \mu \mathrm{g} / \mathrm{mL}$ that was minimum inhibition concentration. $\mathrm{Cu}$ complexes also showed super oxide dismutase (SOD) mimetic activity. $\mathrm{Cu}$ complex with maximum SOD activity possess highest occupied molecular orbital energy (HOMO). These properties showed potential for development of metallo vitamin based medicine [13].

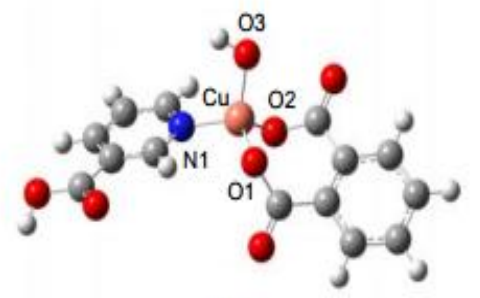

(a)

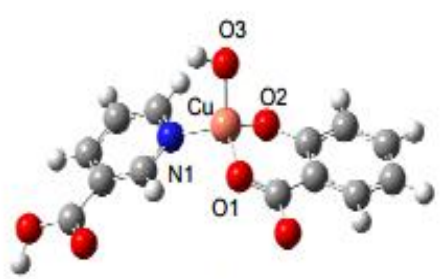

(b)

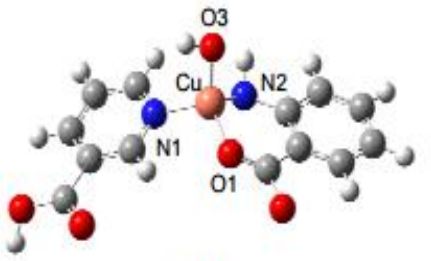

(c)

Fig. 1:-Cu complexes of Nicotinic-phthalic acids (CuNA/Ph) (a), Cu Complex of Nicotinic-salicylic acids CuNA/Sa (b) and $\mathrm{Cu}$ Complex of Nicotinic-anthranilic acids CuNA/Ant (C).

Three metal complexes of Mn such as $[\mathrm{Mn}(\mathrm{tpha})(\mathrm{phen})] \mathrm{n}(1)$, $\left[\mathrm{Mn}(\mathrm{na})_{2}\left(\mathrm{H}_{2} \mathrm{O}\right)_{2}\right] \mathrm{n}(2)$, and $\left\{\left[\mathrm{Mn}(\mathrm{phen})_{2}(\mathrm{OH}) \mathrm{Cl}\right]\right.$ $\mathrm{Cl}(\mathrm{OH})\left(\mathrm{C}_{9} \mathrm{H}_{11} \mathrm{NO}_{2}\right)_{2} 2 \mathrm{H}_{2} \mathrm{O}$ ) (3)were prepared and used X-ray diffraction method to characterize them. Complex 1 show 3D framework complex 2 and 3 show 2D network structure. Positive surface voltage (SPV) ranging in 300$800 \mathrm{~nm}$ was showed for all these complexes. But, there was difference in intensity, position and number of SPV. Solid-state $\mathrm{M}(\mathrm{L})_{2} \cdot \mathrm{nH}_{2} \mathrm{O}$ compounds were synthesized, where $\mathrm{M}$ (bivalent transition metals i.e. $\mathrm{Mn}, \mathrm{Fe}, \mathrm{Co}, \mathrm{Ni}, \mathrm{Cu}$ and $\mathrm{Zn}$ ) and L (nicotinate). Mass losses shown in TG-DTA curves, XRD and infrared FTIR were used to 
characterize and investigate thermal behavior of these compounds. Investigation of thermal behavior of nicotinic acid and its sodium salt was also done. The hydrated transition metal compounds were dehydrated and thermally decomposed in a single step. Different results such as the thermal stability, thermal decomposition and identification of the gaseous products formed in the process of decomposition of the compounds were found [14].

It was studied that copper nicotinic acid complex was used to treat fatty liver in which fat stores in cells of liver and caused problem in structure and functions of liver. It was applied on fatty liver of rat model. $\mathrm{Cu}$ nicotinate complex was applied for 4 weeks. Improvements were observed in rats. Fat droplets disappeared from liver sections. Liver weight, liver trans aminases and alkaline phosphates were decreased and nitric oxides, super oxides; lipid peroxides were changed to normal level. $\mathrm{Cu}$ complex was important for renewal of structure and functions [15].

\section{$\mathrm{Cu}^{+2}$ complexes with imidazole:-}

It was stated that $\mathrm{Mn}, \mathrm{Cu}$ and $\mathrm{Zn}$ complexes with a family of bis-imidazole ligands were synthesized. X-ray crystallography was used to characterize these complexes. A single spacer tetrahedral carbon atom was present between two imidazole rings and formed stable six membered rings having $\mathrm{N}$ and $\mathrm{NO}$ with metals [16].

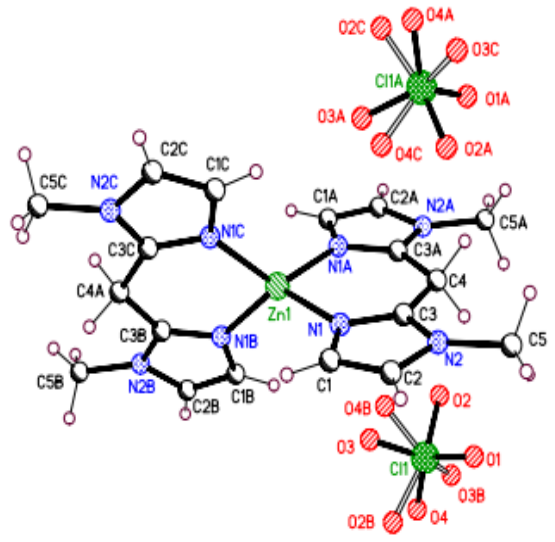

(a)

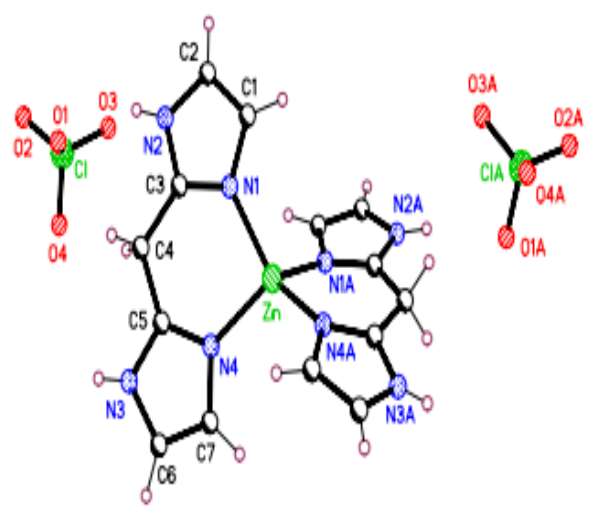

(b)

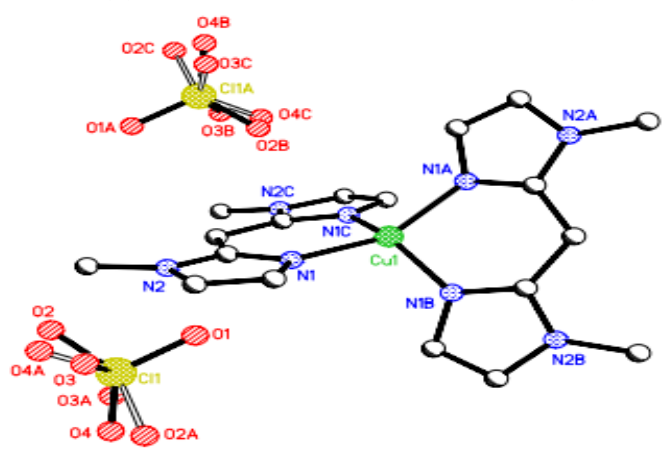

(c)

Fig. 2:-X-ray crystal structure of $\left[\mathrm{Zn}(2-\mathrm{BIM}(\mathrm{Me}))_{2}\right]\left(\mathrm{ClO}_{4}\right)_{2}(\mathrm{a}),\left[\mathrm{Zn}(2-\mathrm{BIM})_{2}\right]\left(\mathrm{ClO}_{4}\right)_{2}$ (b) and (c) $\mathrm{f}[\mathrm{Cu}(2-$ $\left.\mathrm{BIM}(\mathrm{Me}))_{2}\right]\left(\mathrm{ClO}_{4}\right)_{2}$

Two coordination polymers by using hydrothermal conditions were synthesized. Complexes [Cu(ip)(Him) $\left.)_{2}(\mathrm{DMF})\right]$ $\mathrm{H}_{2} \mathrm{O}$ (4) and $\mathrm{Co}(\mathrm{ip})(\mathrm{Him})_{2}(5)$, (ip = isophthalate, Him = imidazole) has been analyzed by using single X-ray diffraction method and it showed that 1D zigzag of metal-organic chains interlinked through hydrogen bonding and (p-p) interactions to form 3-D structure. By using elemental analysis, IR and UV-VIS techniques were used for the characterization of synthesized complexes. Anti-ferromagnetic interaction was observed in magnetic centers of complex 2 through results [17]. 


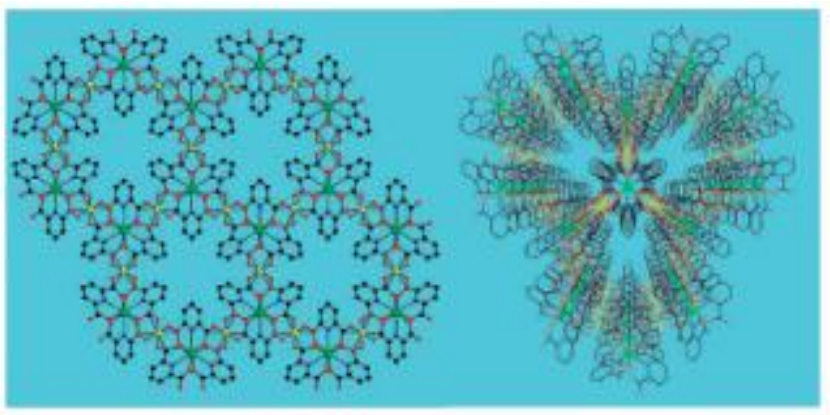

Fig. 3:-Left: View of a [001] projection of the Ln-Co series accentuating the column channels. Right: 3D framework with nanosized channels. Color code: green, Ln; yellow, Co; red, O; blue, N; black, C

Complexes were prepared by using 1-(3-Aminopropyl) imidazole (Apim) and salicylaldehyde. Schiff based ligands and imidazole aldehydes coordinate with metals (Zn (II), Cu (II) and Ag (I). Crystal structures of Silver (I) complex and two free ligands were formed. $\mathrm{Cu}$ (II), $\mathrm{Zn}$ (II) and their free ligands showed inactive nature against microbial pathogens. Anti-bacterial and good anti-fungal activity was shown by Ag (I) complexes [18].

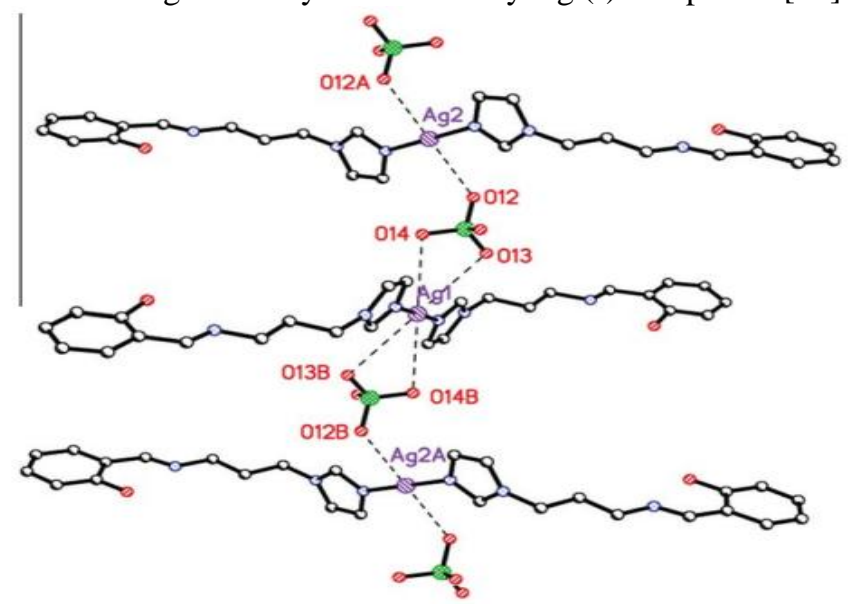

Fig. 4:-Crystal Structure of $\left[\mathrm{Ag}(\mathrm{Apim})_{2}\right] \mathrm{ClO}_{4}$

Two one dimensional compounds of $\mathrm{Cu}$ (II) and Co (II) were prepared and analyzed; Complex 7 was formed by linear trinuclear $\mathrm{Cu}$ (II) subunits and $\mu$-hydroxo and $\mu$-carboxylato bridges that showed that there was strong intratrimer anti ferromagnetic and weak inter-trimer anti ferromagnetic coupling with $2.011 \mathrm{~g}$ value [19].Four complexes of $\mathrm{Cu}$ (II) with imidazole having formulas $\mathrm{Cu}\left(\mathrm{CH}_{2}=\mathrm{CH}-\mathrm{COO}\right)_{2}(\mathrm{imH})_{2}(8), \mathrm{Cu}_{2}\left(\mathrm{CH}_{2}=\mathrm{CH}-\mathrm{COO}\right)_{4}(9), \mathrm{Cu}\left[\mathrm{CH}_{2}=\right.$ $\mathrm{C}\left(\mathrm{CH}_{3}\right)-\mathrm{COO}_{2}(\mathrm{imH})_{2}(10)$ and $(11)($ where $\mathrm{imH}=$ imidazole) were synthesized.IR, ESR and electronic reflectance spectroscopies were used for characterization. In complex 10 single crystal X-ray diffraction showed that, $\mathrm{Cu}$ was central atom of square planar structure in Tran's position with two $\alpha$-methacrylate groups that were monodentate and two ligands of imidazole. Two dimensional supramolecular compounds were formed by linkage of neighboring units by hydrogen bonding. Complex 8 and 10 were same, but 9 and 11 were having structure of binuclear cage. In 9, 11 complexes, spin coupling between unpaired electrons of $\mathrm{Cu}$ atom were observed but not in complex 8 and 10. Complex 9, 11 showed square planar geometry while 8, 10 showed tetragonal. All these four complexes were synthesized by reaction of $\mathrm{Cu}(\mathrm{II})$ imidazole and carboxylate in methanol [20]. 


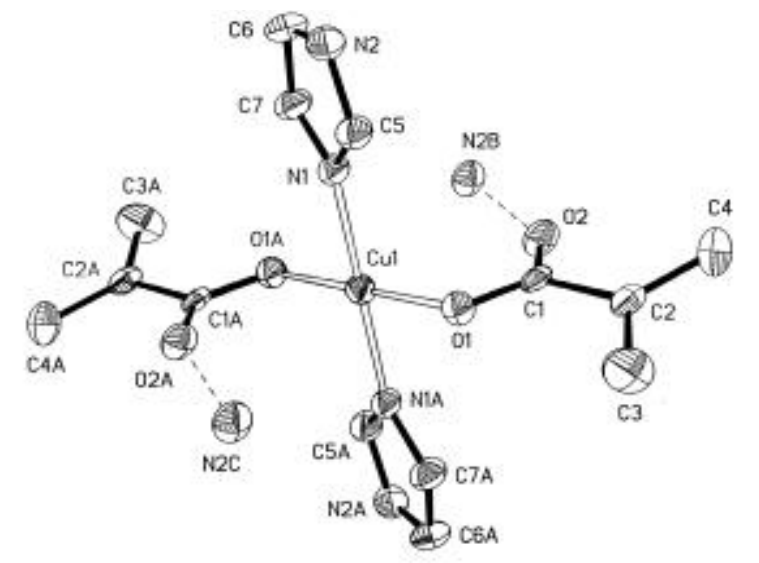

Fig. 5:-ORTEP drawing of $\mathrm{Cu}[\mathrm{CH} 5 \mathrm{C}(\mathrm{CH})-\mathrm{COO}](\mathrm{imH})$

It was stated that complexes of $\mathrm{Cu}$ like $\{$ Bis[(heterocycle)ethyl]amine)copper was formed by the reaction of at least imidazole with 0.5 equivalent dioxygen having $78^{\circ} \mathrm{C}$ and give peroxo complex containing purple color. Above mentioned complexes having pyridine as well as imidazole donors and they shows absorbing capacity at $538 \mathrm{~nm}$, $435 \mathrm{~nm}$ and $332 \mathrm{~nm}$. It was not reactive at low temperature with acid and triphenylphosphme. X-ray crystallography shown structure of its complex and has T-shaped structure [21].

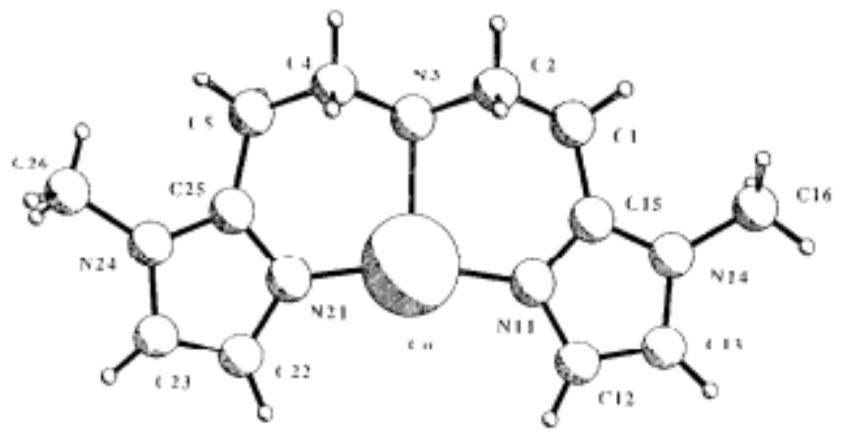

Fig. 6:-Crystal Structure of $\{\operatorname{Bis}[($ heterocycle $)$ ethyl $]$ amine $)$ copper

It was stated that $\mathrm{Cu}$ (II) complexes were synthesized with imidazole. Complex [Cu (asp)- L,J was formed where asp was anion of aspirinate. Different techniques like elemental analysis, magnetic moments and IR and ESR spectroscopy techniques were used for the characterization of that compound. Tetrakis compound containing imidazole and $\mathrm{N}$-methyl imidazole showed tetragonal six coordinated structure with $(\mathrm{CuN} 4+0)$ chromophore. Tetragonal distorted octahedron geometry was shown by bis adduct of 1, 2-dimethyl imidazole, with $\mathrm{CuN}_{2} \mathrm{O}_{2}$ chromophore at Trans distorted square planar environment. Rather than dimeric structure, monomeric structure was discussed due to electronic and steric effects of imidazole ligands [22].

The crystal formation and different temperatures and analysis of magnetic property associated with new thiocyanato based copper(II) complex with bi-imidazole, may be 2-(20-pyridyl)imidazole) (pyim) seeing that co-ligands, usually reported. Complex 1 contains tri-nuclear variety central cations as well as peripheral anions usually were linked through individual bridges of thiocyanate. Complexes 2 and 3 were comprised of neutral copper (II) ion snow chains with one (2) and two (3) bridges of thiocyanato. By the formation of coordination sphere, each copper atom attached with bidentate and N-Donor thiocyanate group. The values of intra-molecular (1) and also intra-chain (2 and also 3) copper to copper separation usually found in the range of 5. 6143, 5. 6744 and $6.0797 \AA$. Magnetic susceptibility proportions for 1-3 within the temperature range 1.9-295 E showed the phenomenon of weak intramolecular and also intra-chains anti-ferromagnetic interactions. The nature as well as magnitude of magnetic interactions were elaborated with respect to particular respective structures and compared these with those who mentioned for linked system [23]. 


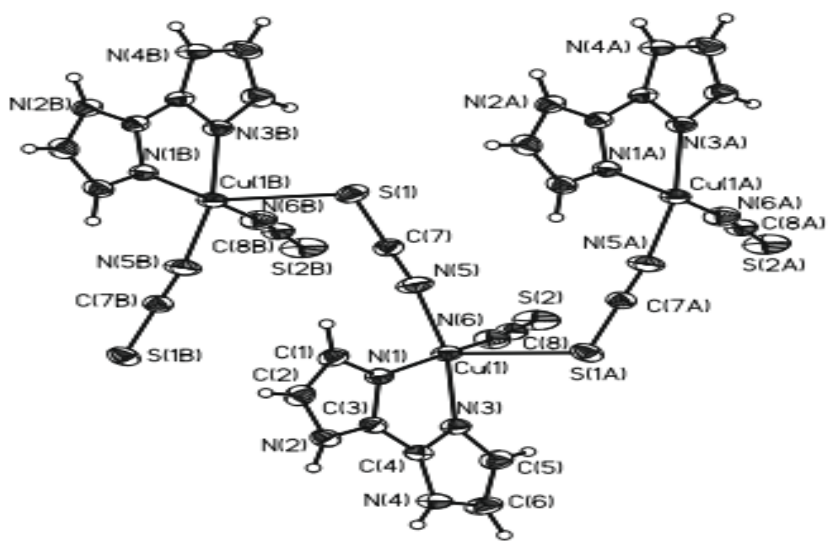

Fig. 7:-Crystal Structure of $\left[\mathrm{Cu}\left(\mathrm{H}_{2}\right.\right.$ bim $\left.)(\mathrm{NCS})_{2}\right] \mathrm{n}$

Coordination complexes of imidazole and benzimidazole replaced by radicals of nitronyl nitroxide along with transition metal ions along with ions of lanthanide were explained in the wayof their magnetic properties. With the $3 \mathrm{~d}$ metals chemical substances the crystal houses showed different dimensions with metal-nitroxide. The uninuclear processes were separated along with most ions of metal from the collection of transition metals. One copper (II) intricate showed a ferromagnetic coupling of copper (II)-radical i.e., $(\mathrm{J}=+75 \mathrm{~cm}-1)$ while to the other mononuclear chemical substances, mostly with manganese (II), anti-fero-magnetic interactions of metal-radical. Complexes of manganese (II) were one and two-dimensional which showed effects that lead to very weak ferromagnetism. Ions of lanthanide were trivalent such as $\mathrm{La}(\mathrm{III}), \mathrm{Gd}(\mathrm{III})$ along with $\mathrm{Eu}(\mathrm{III})$, regarding uninuclear compounds were formed that center of metal was bound to nitroxide radicals along with ancillary ligands. Unexpectedly, Gd(III) radical communications were found as an anti-ferromagnetic in contrast with others, founding along with previously determined theoretical products. Through magnetic studies, properties of Optics for lanthanide compounds have been determined and shortly explained [24].
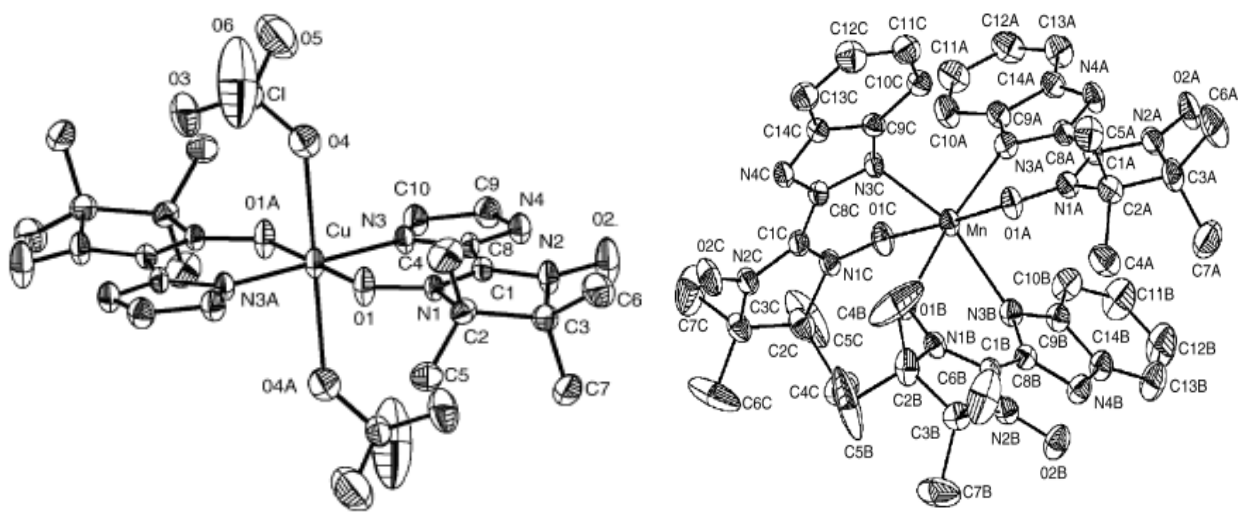

(a)(b)

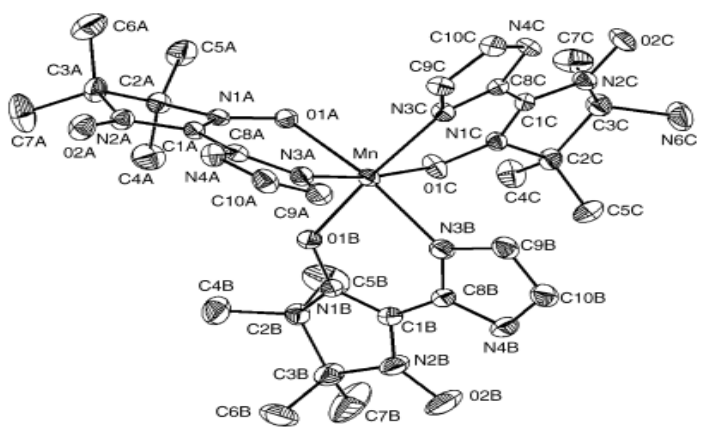

(c)

Fig. 8:-Molecular structure of complex $\left[\mathrm{Cu}(\mathrm{NITImH})_{2}\left(\mathrm{ClO}_{4}\right)_{2}\right](\mathrm{a})$, mer-[MnII $\left.(\mathrm{NITBzImH})_{3}\right]^{2+}(\mathrm{b})$ and fac$\left[\mathrm{MnII}(\mathrm{NITImH})_{3}\right]^{2+}$ 
For the formation of coordination and hydrogen bond, $\mathrm{Cu}$-complexes and Schiff based ligands which were usually composed of imidazole groups which also having a specifically donor as well as acceptor character. They function as ligands or sometimes as self-complementary towards the construction of specific structures forming various hydrogen or possibly coordination bonds. For such type of complexes, monomers were stabilized themselves like protonated species in acidic media, while in basic media, synthesized $\mathrm{N}$-donor imidazole which show coordination with $\mathrm{Cu}$ ions bonded with hydrogen bond with their adjacent imidazole group showing specific coordination with different ligands attached with central metal ion. By adjusting $\mathrm{pH}$, a monomer and an oligomer were reversible or an interconvertible with each other [25].

Stable complexes of $3 \mathrm{~d}$ metals such as $\mathrm{Mn}$ (II), $\mathrm{Cu}$ (II), Co (II), Ni (II) and $\mathrm{Cr}$ (III) with ligands like PEF (Pefloxacin) and imidazole had been prepared. These were characterized by using techniques like X-ray crystallography, FT-IR and other elemental analysis. Their magnetic properties were also explained. The results shown that Pefloxacin behaved like a bidentate ligand and the metal ions from the pyridone oxygen also sometimes from the oxygen of carboxylic group besides for the complex of silver (I), the place that the metal ion chelating towards the nitrogen of piperazinyl. TGA and DTA were the thermal behaviors that had also been also performed around the complexes so that you can study their stabilities as well as activation energies, DE, entropies DS; enthalpies DH and Horowitz-Metzeger procedure calculations were used to know order of reactions $\mathrm{n}$. The mixed ligands processes were determined with regards to antibacterial activity in opposition to two species of bacteria, named as Staphylococcus aureus and Escherichia coli. Antifungal verification was explained in opposition to two species (Aspergillus flavus as well as Candida albicans). These compounds s under study were known [26].

A pair of sandwich-type complexes $\mathrm{Na}_{9 \mathrm{n}}\left(\mathrm{Cu}(\mathrm{imi})_{4}\left(\mathrm{H}_{2} \mathrm{O}\right)_{2}\right)_{1.5 \mathrm{n}}\left(\mathrm{Cu}(\mathrm{imi})_{4}\left(\mathrm{H}_{2} \mathrm{O}\right)_{\mathrm{n}} \quad\left[\left\{\mathrm{Cu}(\mathrm{imi})_{4}\right\}\left\{\mathrm{Na}\left(\mathrm{H}_{2} \mathrm{O}\right)_{2}\right\}\right.\right.$ ${ }_{3}\left\{\mathrm{Cu}_{3}(\mathrm{imi})_{2}\left(\mathrm{H}_{2} \mathrm{O}\right)\left(\mathrm{XW}_{9} \mathrm{O}_{33}\right)_{2}\right]_{2 \mathrm{n}} \cdot\left(\mathrm{xH}_{2} \mathrm{O}\right)_{\mathrm{n}}$ (imi ) imidazole, $\mathrm{Bi}(1), \mathrm{Sb}(2), 42.5$ (1), 40 (2) were already prepared and characterized structurally. Main frameworks of 1 and 2 complexes were made from sandwich-like $\left[\left\{\mathrm{Na}^{2}\left(\mathrm{H}_{2} \mathrm{O}\right)_{2}\right\}\right.$ $\left.{ }_{3} \mathrm{Cu}_{3}(\mathrm{imi})_{2}\left(\mathrm{H}_{2} \mathrm{O}\right)\left(\mathrm{XW}_{9} \mathrm{O}_{33}\right)_{2}\right]_{9^{-}}(\mathrm{X}) \mathrm{Bi}$ or perhaps anions of $\mathrm{Sb}$ and cations of $\left[\mathrm{Cu}(\mathrm{im})_{4}\right]^{2+}$. The $\mathrm{Cu}^{2+}$ and $\mathrm{Na}^{+}$ions within the central belt were generally show coordination by $\mathrm{R}-\left[\mathrm{XW}_{9} \mathrm{O}_{33}\right]_{9}$ - items, imi, and molecules of water to form $\mathrm{CuO}_{4}(\mathrm{imi}), \mathrm{CuO}_{4}\left(\mathrm{H}_{2} \mathrm{O}\right)$, and $\mathrm{NaO}_{4}\left(\mathrm{H}_{2} \mathrm{O}\right)_{2}$ groups in which in turn $\mathrm{Cu}^{2+}$ ions were generally modified partially along with imi ligands. These kinds of connected groups instead of forming a six-membered wedding ring with six $\mathrm{R}-\left[\mathrm{XW}_{9} \mathrm{O}_{33}\right]_{9}$ - items. Neighboring anions were more connected by $\left[\mathrm{Cu}(\mathrm{im})_{4}\right]^{2+}$ cations to show anionic string, which was first affected as sandwich-type tungsto-bismuthate system. Two types connected with separated copper compounds and ions of sodium were generally located as counter ions, which presented interesting cage like structures by three-dimensional pickings' of 1 and 2 . The magnetic houses for 1 and 2 complexes both reveal prominent anti-ferromagnetic relationships among trinuclear $\mathrm{Cu}$ (II) groups [27].

A supramolecular arrangement had been synthesized by p-sulfonat othiacalix[4]are or copper(II)/imidazole by hydrogen bonding. It showed that p-sulfonato thiacalix[4]are using 1, 2-oppositearrangement may attach copper(II) along with a bis-tridentate coordination method, and moreover exhibits behavior of charge-transfer [28].

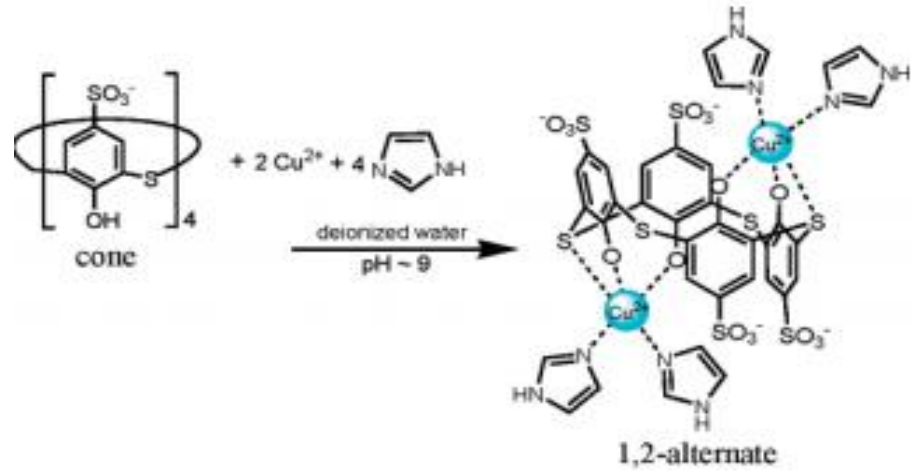

Fig. 9:-Synthesis of Cu/imidazole Complex with 1,2-Alternate p-Sulfonatothiacalix [4]arene 

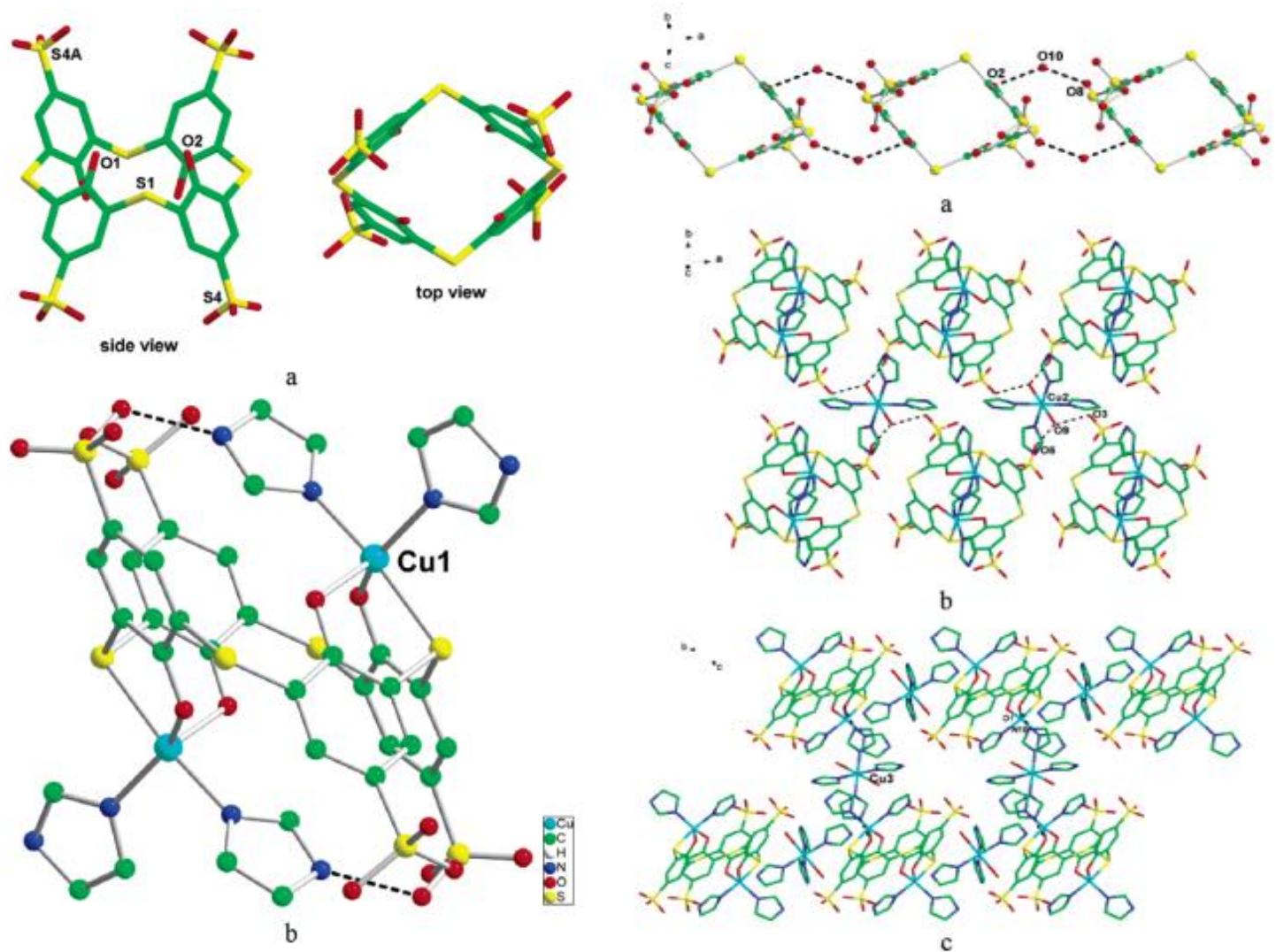

Fig. 10:-X-ray structure of complex 1: (a) view showing the 1,2-alternate conformation of STC4A; (b) view showing the bis-tridentate coordination mode of STC4A with $\left[\mathrm{Cu}(\text { imidazole })_{2}\right]^{2+}$ cations

The binuclear complex of copper (II) (complex 1) along with taurine Schiff bottom and imidazole have been prepared and its structure was seen as X-ray diffraction techniques, necessary analysis, ESI-MS spectrometry, UVvis as well as IR spectroscopy. Single-crystal examination showed that 1 demonstrated the sulfonate-bridged dinuclear copper (II) stores. Two copper atoms were usually five-coordinated and demonstrate a little distorted square pyramidal geometry. All copper atoms were actually attached with three oxygen atoms as well as one atom of nitrogen by different ligands of taurine Schiff bottom, and one atom of nitrogen from imidazole ligand. The actual association between 1 as well as (CT-DNA) seemed to be analyzed by UV-Vis spectroscopy, fluorescence, round dichroism (CD) spectra as well as electrophoresis of agarose gel. Actual results pointed out that 1 could possibly bind to CT-DNA by using an inter-connective method and showed effective cleavage activity. In addition, 1 gave an antitumor effect on cell cycle as well as apoptosis. Cytometric flow of examination showed that MGC-803 cells were catched from the $\mathrm{S}$ phase following treatment by 1 . Fluorescence tiny observation showed which one could produce apoptosis of MGC-803 solar cells [29].

Being unfaithful complex of monoanionic a-hydroxy carboxylates (HLO) using imidazole as a co-ligand has also been synthesized and structurally seen as an X-ray diffraction technique. The complexes of nickel (II) might be described by two formulas: [Ni (HLO) $)_{2}(\mathrm{Imi})_{2}$ ], HLO 2-methyllactate $(\mathrm{HmL})(1)$ as well as mandelate (HM) (2), in addition to $\left[\mathrm{Ni}(\mathrm{HB})_{2}(\mathrm{Imi})_{3}\right]$, HB benzylate (3). In these ingredients atom of nickel was within environment of distorted octahedral. $\left[\mathrm{Cu}(\mathrm{HLO})_{2}(\mathrm{Im})\right]$, HL0 1/4 glycolate (HG) (4), lactate (HL) (5) as well as 2-methyllactate (HmL) (6) were synthesized $\mathrm{Cu}$ complexes that possess geometry of square pyramidal with a distortion analyzed when it comes to the s parameter. The zinc (II) compounds hold the general formula [ $\left.\mathrm{Zn}(\mathrm{HLO})_{2}(\mathrm{Imi})_{2}\right] \cdot \mathrm{xH}_{2} \mathrm{O}$, HLOlactate (HL) in addition to $\mathrm{x} \quad 1=2(7), 2$-methyllactate $(\mathrm{HmL})$ in addition to $\mathrm{x} 0(8)$ in addition to show octahedral geometry. However, the reaction having $\mathrm{H}_{2} \mathrm{~B}$ afforded the particular imidazole complex $\left[\mathrm{Zn}(\operatorname{Imi})_{6}\right](\mathrm{HB})_{2}, \mathrm{HB}^{1 / 4}$ benzylate (9), containing two non-coordinated benzylate items. In most with the complexes the a-hydroxy carboxylato ligands work as bidentate monoanionic methods, apart from throughout 3 , where one particular ligand was uni-dentate. All of the complexes were expanded in frameworks of 2D as well as 3D by way of hydrogen bonding. These compounds were seen as an elemental analysis, FT-IR in addition to UV spectroscopy. Nickel in 
addition to copper complexes had been also studied simply at room temperature permanent magnet susceptibility and temperature ESR spectra were obtained with the copper complexes. Ultimately, all the so-called complexes were investigated thermally [30].

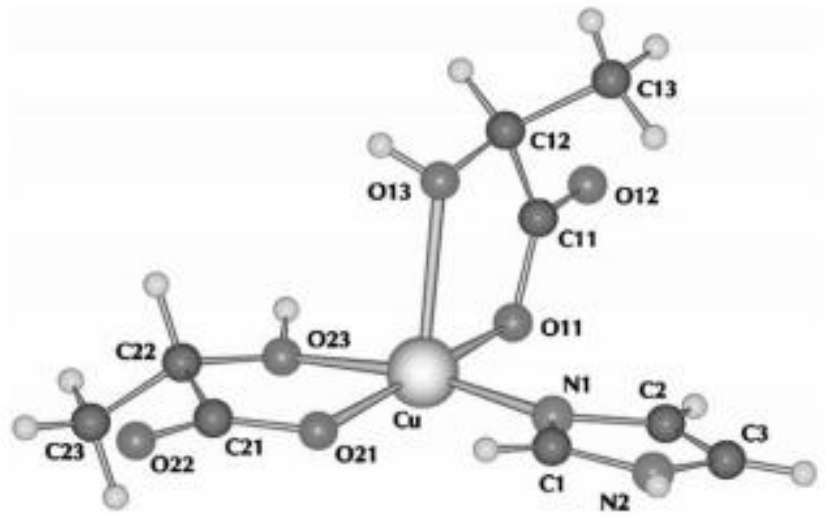

(a)

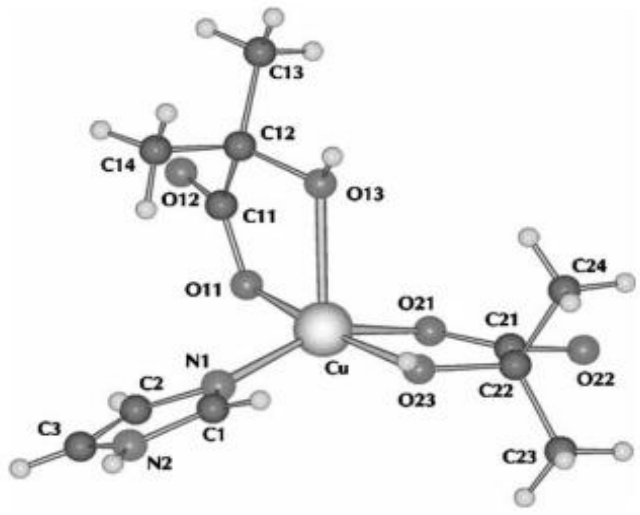

(b)

Fig. 10:-Molecular structure of $\left[\mathrm{Cu}(\mathrm{HL})_{2}(\mathrm{Im})\right](\mathrm{a})$ and $\left[\mathrm{Cu}(\mathrm{HmL})_{2}(\mathrm{Im})\right](\mathrm{b})$

A pair of two new complexes of copper(II) and also coordination of cobalt(II) compounds, $\left\{\left[\mathrm{Cu}(\mathrm{Pht})(\mathrm{Imi})_{2}\right]\right.$ $\left.1.5 \mathrm{H}_{2} \mathrm{O}\right\}_{\mathrm{n}}(1)$ and also $\left[\mathrm{Co}(\mathrm{Pht})(\mathrm{Imi})_{2}\right] \mathrm{n}(2)\left(\right.$ where $\mathrm{Pht}_{2}=$ dianion connected with $\mathrm{o}=$ phthalic acid and $\mathrm{Imi}=$ imidazole) happen to be prepared and structures of their crystals were dependent upon X-ray crystallographic technique. The structures of just one and two consist of $\left[\mathrm{Cu}(\mathrm{Imi})_{2}\right]$ and also $\left[\mathrm{Co}(\mathrm{Imi})_{2}\right]$ units respectively, connected by bridging 1, 6-phthalate ions to form long chains. There were two $\mathrm{Cu}$ atoms that were independent inside structure 1; each and every copper (II) center explores an almost rectangular planar mode of coordination with two atoms from diverse phthalate ions and also two atoms of $\mathrm{N}$ connected with Imi. In complex 2, cobalt (II) atoms usually were coordinated tetrahedrally. The three-dimensional constructions were stabilized by long hydrogen bonding in both processes. Preliminary results show that catalytic activity within the oxidation of cyclohexene was shown by one and two exhibiting utilizing hydrogen peroxide while oxidant under cardiovascular conditions at optimum temperature [31].

Raman spectra were actually formed for ligands like imidazole, histidine, imidazolium and $\mathrm{Cu}$ complexes of imidazole on $229 \mathrm{~nm}$ to $200 \mathrm{~nm}$ wavelengths. It was offered by Raman shifted laser beam. In all events, maximum excitation was showed on $-218 \mathrm{~nm}$ and $-204 \mathrm{~nm}$, inside broad absorption digital band at $-210-\mathrm{nm}$. By the use of ring enhancement patterns, $r-r *$ transitions in the ring of imidazole were identified. Alternations connected with band of Raman frequencies and also intensities were shown. When imidazole was protonated or substituted that has functional group of methyl. Methyl imidazole spectra's and histidine spectra's were same. There was inferior effect on complex of $\mathrm{Cu}^{+2}$ with imidazole. Some wave numbers shifted the ring modes. Change of charge transfer of $\mathrm{Cu}^{+2}$ was placed close to $240 \mathrm{~nm}$. N-Cu stretches mode of enhancement were comparable to that of $\mathrm{Cu}$ and (ethylenediamine)? + Which included its charge-transfer band at that wavelength? The enhancement of the 950-cm-' mode of ring was additionally observed at $240 \mathrm{~nm}$. Tries to attain R-R spectra in your neighborhood $(-300 \mathrm{~nm})$ of the weakest imidazole (r): $\mathrm{Cu}^{2+}$ charge-transfer changes were not successful. But differences inside positions of the band might be used to differentiate between protonated, un-protonated, and also $\mathrm{Cu}$-bounded histidine residues with proteins, all round enhancement was normal, and histidine impulses were impossible to detect inside presence of the higher signals from aromatic rings which can exist in many proteins, as it was explained with regards to the $\mathrm{Cu}$ proteins stellacyanin [32].

Several din-uclear copper (II) complexes that were acetato-bridged with 5-nitroimidazoles (CuAcNtrim) as well as the known copper-acetato-metronidazole were already synthesized by the route of friendly environment along with spectroscopic characterization. The Cu-AcNtrim compounds of formula $\left[\mathrm{Cu}_{2}\left(1-\mathrm{O}_{2} \mathrm{CCH}_{3}\right)_{4} \mathrm{Ntrim}_{2}\right]$, exactly where Ntrim = metronidazole (1), secnidazole (2), tinidazole (3) or perhaps nimorazole (4), showed dimeric copperacetato paddle-wheel setted up with Ntrim that was axial ligands synchronized to copper(II) ions by the $\mathrm{N}_{3}$ atoms from the rings of imidazole. EPR data point out behavior that was antiferromagnetic due to that novel series of copper complexes. With the increase in basicity from the Ntrim terminal ligand the coupling constant may be found to decrease. The $\mathrm{Cu}-\mathrm{Ac}-\mathrm{Ntrim}$ complexes as well as the correspondent Ntrim parent drugs showed radio sensitizer 
properties regarding Hep2 (human larynx cancer) mobile line in vitro. The better enhancement of radio sensitizer exercise upon coordination to the Ntrim drug to copper(II)has the strongest $\mathrm{Cu}-\mathrm{N}$ trim connection may be found for your nimorazole compound and it exhibited the best lipophilicity within the association of $\mathrm{Cu}$-Ac Ntrim complexes [33].

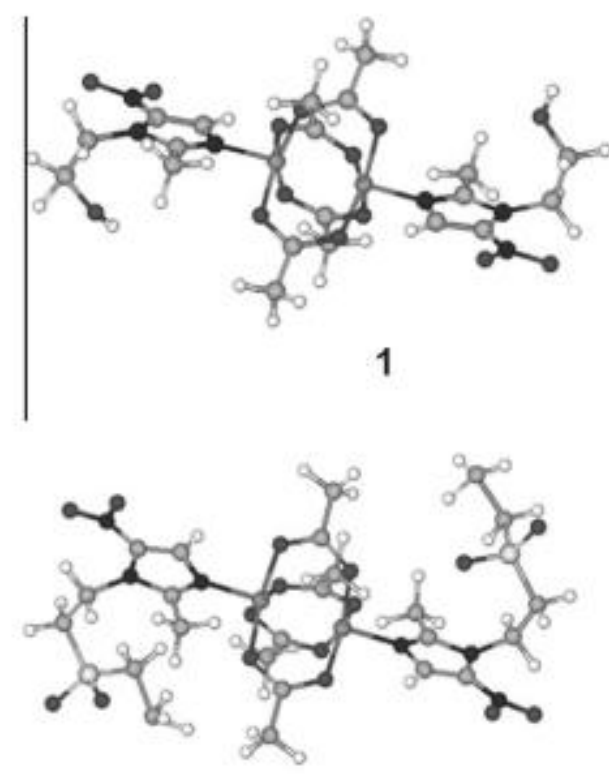

3

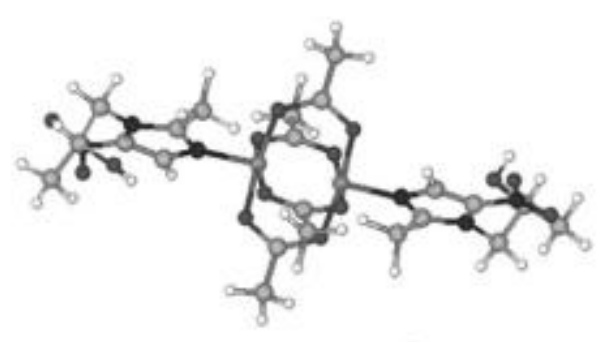

2

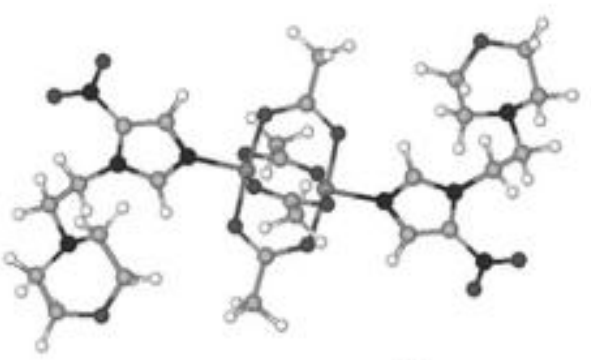

4

Fig. 11:-Molecular structures of $\left[\mathrm{Cu}_{2}(\mathrm{Ac})_{4}(\mathrm{Metrim})_{2}\right](1),\left[\mathrm{Cu}_{2}(\mathrm{Ac})_{4}(\mathrm{Secnim})_{2}\right](2),\left[\mathrm{Cu}_{2}(\mathrm{Ac})_{4}(\mathrm{Tinim})_{2}\right](3)$ and $\left[\mathrm{Cu}_{2}(\mathrm{Ac})_{4}(\mathrm{Nimim})_{2}\right](4)$

The catalytic activity of a special $\mathrm{Cu}$-salen variety complex in $\mathrm{N}$-arylation involving arylboronic acids with water and anilines was reported here. This protocol was located to be favorable for many electronically improved aryl boronic acids and also anilines with good output of the isolated product. Additional the scope with this protocol has been spread towards the formation of several $\mathrm{N}$-aryl imidazoles with iso-propanol ligand [34].

\section{$\mathrm{Mn}^{+2}$ complexes with nicotinic acid:-}

Complex of nicotinic acid with manganese in sodium Meta silicate ligand was formed and single crystal X- ray diffraction technique was used for structure determination. There were different dimensions of cell in space group for complex crystal. 3D complex was obtained by bridging carboxylate group with two central metal atoms. Intermolecular hydrogen bonds stabilized the crystal structure. FT-IR spectral studies were used for the identification of functional groups and the bonding sites of the ligand with metal atoms. Thermal properties and stability of crystals were known by TGA and DTA [35]. Hetero metallic complex, $\left[\mathrm{Ni}_{2} \mathrm{Mn}\left(\mathrm{N}_{3}\right)_{2}\left(\mathrm{nic}_{4}-\left(\mathrm{H}_{2} \mathrm{O}\right)_{2}\right] \mathrm{n}\right.$ where nic =nicotinate) was also prepared. It was formed by using $\mathrm{MnCl}_{2} .4 \mathrm{H}_{2} \mathrm{O}, \mathrm{Ni}\left(\mathrm{NO}_{3}\right)_{2} \cdot 6 \mathrm{H}_{2} \mathrm{O}, \mathrm{NaN}_{3}$ and nicotinic acid by "one step" method. $\mathrm{Ni}-\mathrm{Mn}-\mathrm{Ni}$ was used to describe 3Dstructure of the complex and nicotinate linked that trimer [36] (Jiaoet al., 2013). Complex hybrid mixtures of nicotinic acid, methane and lycopodium were prepared and studied their explosion behavior and flammability. Explosion tests were performed in explosion vessel of 20L. Exceptional behavior of hybrid complex with equal amount of nicotinic acid and lycopodium was observed and noticed that it was most reactive than other mixtures [37].

The iso nicotinic acid N-oxide complex of $\mathrm{Mn}$ (II) element was prepared and element analysis and also X-ray crystallography were used for characterization of complexes. Ions of $\mathrm{Mn}(\mathrm{II})$ in the complex to have coordination with 6-8 molecules of water, plus the coordination Number could be six with the Mn(II) ion. Spectras of FTIR spectra with the in the stove $4000-400 \mathrm{~cm}^{-1}$ were recorded for the free iso nicotinic chemical $\mathrm{p}$ N-oxide (INO) Complex. Cathodo luminescence spectra represented as (CL) from the Mn(II) complex happened to be analyzed. The luminescence information was recorded at $480 \mathrm{~nm}$ regarding the emission music group. The green luminescence) arises at $(480 \mathrm{~nm})$ from the $\mathrm{Mn}^{2+}$ Change over 4T1 (4G)! 6A1 (6S). The item showed weak vibrionic design, small life time's fewer than 250 ls, and also indicated that Mn 2p can be octahedrally coordinated, occupied 
websites with same distortions. The lifetime and intensity was heat range dependent with the signal, and the boundaries were shown for your emissions series at $480 \mathrm{~nm}$ [38].

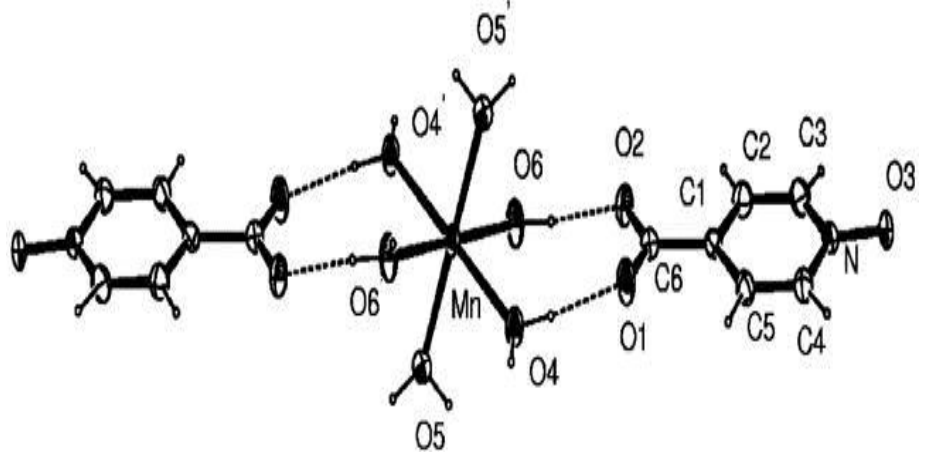

Fig. 12:-Molecular structure of $\left[\mathrm{Mn}\left(\mathrm{H}_{2} \mathrm{O}\right)_{6}\right]\left[\mathrm{O}-\mathrm{C}_{6} \mathrm{H}_{4} \mathrm{NO}_{2}\right]_{2}$

About three new isostructural coordination polymers, such as, $\left[\mathrm{M}_{4}\left(\mu_{3}-\mathrm{OMe}\right)_{4}(\mathrm{nic})_{4}\right]_{\mathrm{n}}\left[\mathrm{M}=\mathrm{Mn}^{\mathrm{II}}(1), \mathrm{Fe}^{\mathrm{II}}(2)\right.$, and also $\mathrm{Co}^{\mathrm{II}}$ (3); Hnic= nicotinic acid], happened to be prepared solv0 thermally and also characterized magnetically. X-ray diffraction analysis revealed that substances 1-3 were having frameworks of three-dimensions, which might be prepared through $\mathrm{M}_{4}\left(\mu_{3}-\mathrm{OMe}\right)_{4}$ building like cubane obstructs and bridged as nic- anions. Measurements of variabletemperature permanent magnetic susceptibility indicated that they all showed antiferromagnetic conduct with variety of intra-cubane coupling constants. Complex 1 exhibited spin-frustration conduct, and was fixed that has a two-J model from the temperature range involving 2-300 K, giving $\mathrm{J} 1=-0.95$ and $\mathrm{J} 2=-2$. Twenty three $\mathrm{cm}^{-1}$ Complexes 2 and also 3 were fixed with all the same model from the temperature range involving 30-300 K and also $40-300 \mathrm{~K}$ to provide the exchangeable coupling constants $\mathrm{J}_{1}=-2$. Forty-nine, $\mathrm{J}_{2}=$ several. $84 \mathrm{~cm}-1$ and also $\mathrm{J}_{1}=-4.16, \mathrm{~J}_{2}=$ 5 , Forty-four $\mathrm{cm}^{-1}$, respectively. Two coordination polymers of azido manganese (II) were given by reactions of $\mathrm{Mn}^{\mathrm{II}}$ ions along with azido ligands with the existence of nicotinic/isonicotinic acids, polymers were, $\left[\mathrm{Mn}_{3}\left(\mathrm{~L}_{1}\right)_{2}\left(\mathrm{~N}_{3}\right)_{4}\right]_{\mathrm{n}} 3 \mathrm{NH}_{2} \mathrm{O}(1)$ and also $\left[\mathrm{Mn}_{2}\left(\mathrm{~L}_{2}\right)\left(\mathrm{N}_{3}\right)_{3}\right]_{\mathrm{n}}(2)$, in which $\mathrm{L} 1=$ nicotinate and also $\mathrm{L} 2=$ isonicotinate, along with variety of topological constructions. Complex 1 involves $2 \mathrm{D}$ azido-Mn(II) aircraft, which was even more coordinated by $\mathrm{L}_{1}$ in order to create a 3D construction with un-parallel 3, 6-connected 4-nodal online topology, and complicated 2 presented the unprecedented 3, four, 6-connected 6-nodal three dimensional azido-Mn(II) structure with $\mathrm{L}_{2}$ because of co-ligand. Magnetic susceptibility sizes showed prominent antiferromagnetic coupling current in 1 and 2 also. Complex 1 could be a spin-competitive system and entered right into transition of a low ferromagneticto-magnetic phase with the sensitive 1 temperature range regarding $6 \mathrm{~K}$ on account of spin canting. Complex 2 could be antiferromagnetic and revealed field-induced spin-flop habits [39].

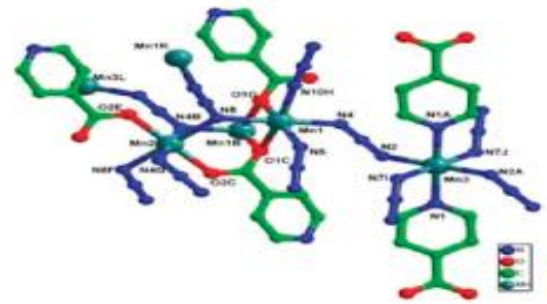

(a)

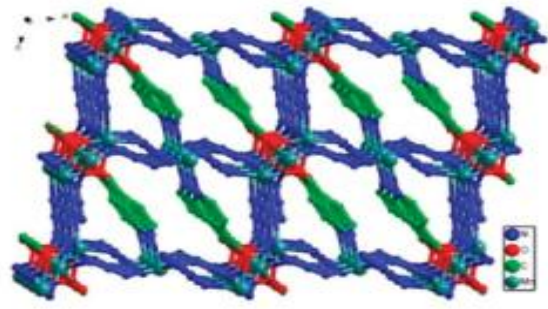

(c)

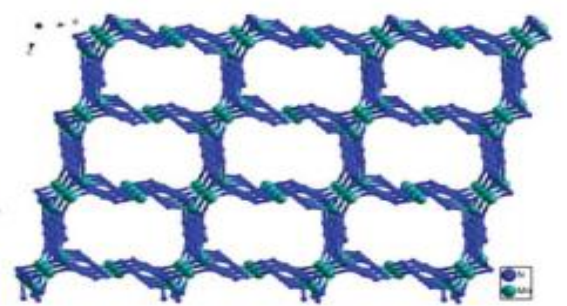

(b)

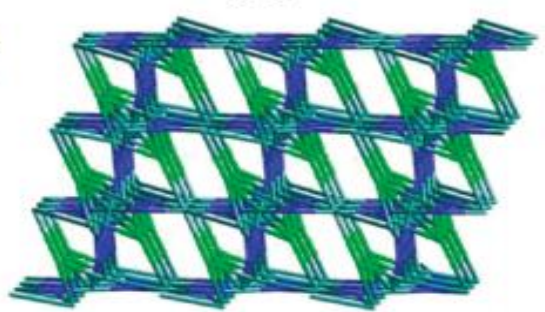

(d)

Fig. 13:-(a) Coordination and linkage modes of the ligands and $\mathrm{Mn}^{\mathrm{II}}$ ions (b) Azido- $\mathrm{Mn}^{\mathrm{II}}$ 3D net (c) 3D structure (d) Topology network of $\left[\mathrm{Mn}_{2}\left(\mathrm{~L}^{2}\right)\left(\mathrm{N}_{3}\right)_{3}\right]_{\mathrm{n}}(2)$ 


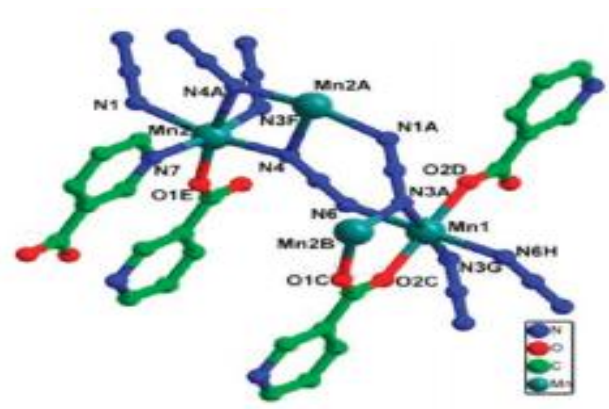

(a)

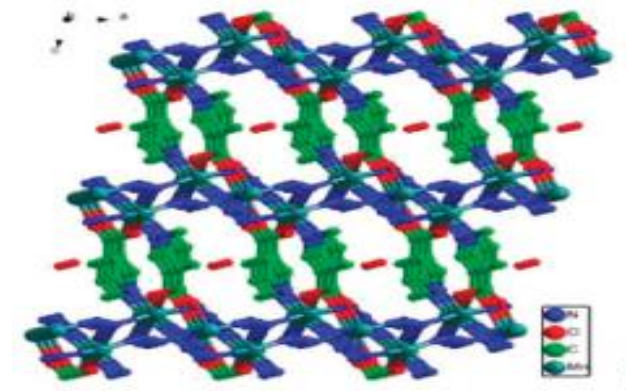

(c)

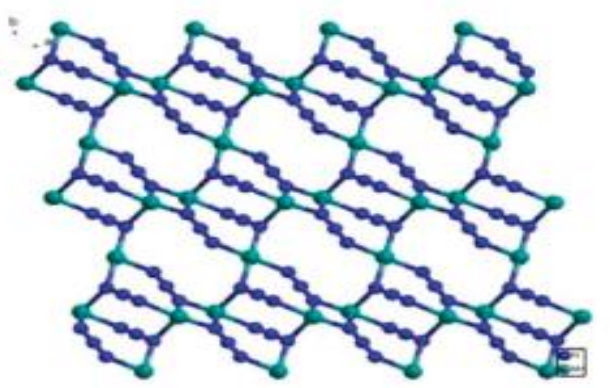

(b)

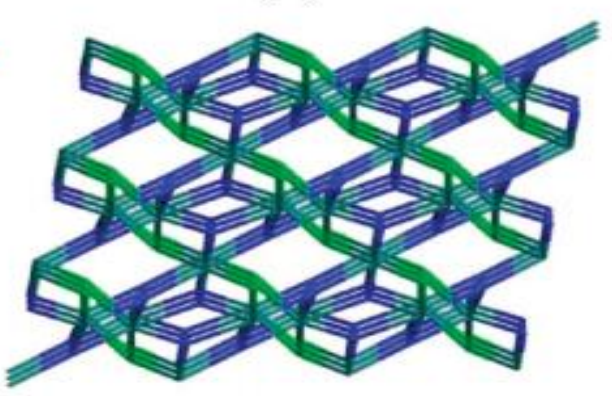

(d)

Fig. 14:-(a) Coordination and linkage modes of the ligands and $\mathrm{Mn}^{\mathrm{II}}$ ions (b) Azido-Mn ${ }^{\mathrm{II}}$ $3 \mathrm{D}$ net (c) $3 \mathrm{D}$ structure (d) Topology network of $\left[\mathrm{Mn}_{3}\left(\mathrm{~L}^{1}\right)_{2}\left(\mathrm{~N}_{3}\right)_{4}\right]_{\mathrm{n}} \cdot 3 \mathrm{nH}_{2} \mathrm{O}(1)$

Under the conditions of hydrothermal, about three coordination compounds, such as $\left[\mathrm{Mn}_{2}(5 \text {-phenoxonic })_{2}\right](1)$, $\left[\mathrm{Cd}_{2}(5 \text {-phenoxonic) })_{2}\right](2)$, along with $\left[\mathrm{Fe}_{2}(5 \text {-phenoxonic })_{2}\right](3)$, were prepared under hydrothermal conditions and simply X-ray diffraction technique was used for characterization of the structure. The structure involving compound 1 can be defined as a characterized metal-organic characterized framework that's prepared by two forms of unique crystallo graphical cations of Mn along with a kind involving $\mu 6-5$-phenoxonicotinato bridging ligand, having a 6 , 6-connected 3.410.64 49.66 topology construction. Using $\mathrm{Cd}$ along with ions of $\mathrm{Fe}$ instead of ions of $\mathrm{Mn}$ respectively, two new compounds 2 and 3 usually were obtained that happen to be isostructural with 1 . Furthermore, magnetic property of compound 1 was investigated [41].

Several manganese(II) coordinated compounds, such as $\left[\mathrm{Mn}\left(\mathrm{L}^{2}\right)(\mathrm{phen})\left(\mathrm{H}_{2} \mathrm{O}\right)\right]_{\mathrm{n}} \quad \mathrm{nH} \mathrm{H}_{2} \mathrm{O} \quad(\mathrm{a}), \quad\left[\mathrm{Mn}\left(\mathrm{L}^{2}\right)(2, \quad 20-\right.$ bipy) $\left.\left(\mathrm{H}_{2} \mathrm{O}\right)\right] \mathrm{n} .2 \mathrm{nH}_{2} \mathrm{O}$ (b) along with $\left[\mathrm{Mn}\left(4,4{ }_{0} \text {-bipy }\right)_{2}\left(\mathrm{H}_{2} \mathrm{O}\right)_{2}\right] \mathrm{n} 2 \mathrm{~nL}^{3}$ (c) (phen = 1, 10-phenanthroline, a couple of, 20-bipy = a couple of, 20-bipyridine, 4, 40-bipy = 4, 40-bipyridine, L2 = 2-sulfonato-nicotinate along with L3 = 2(3-carboxy-pyridine-2-yl disulfanyl)-nicotinic chemical $\mathrm{p}$ anion), have also synthesized from inside reactions of metal and ligand. By in situ oxidation connected with 2-mercaptonanicotinic acid (L1) in the presence of distinct coligands, the unpredicted oxidative production in disulfide bond along with $\mathrm{S}-\mathrm{O}$ bond were generally seen [42]. 


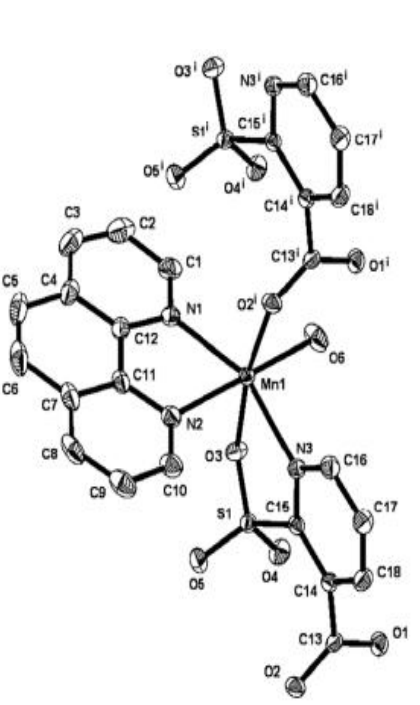

(a)

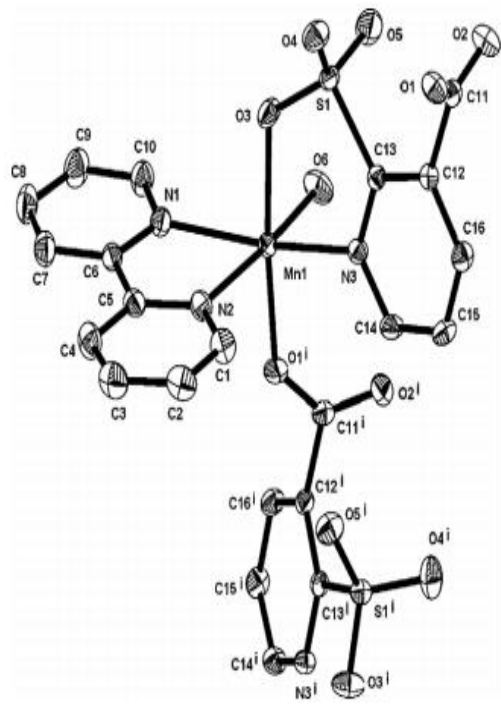

(b)

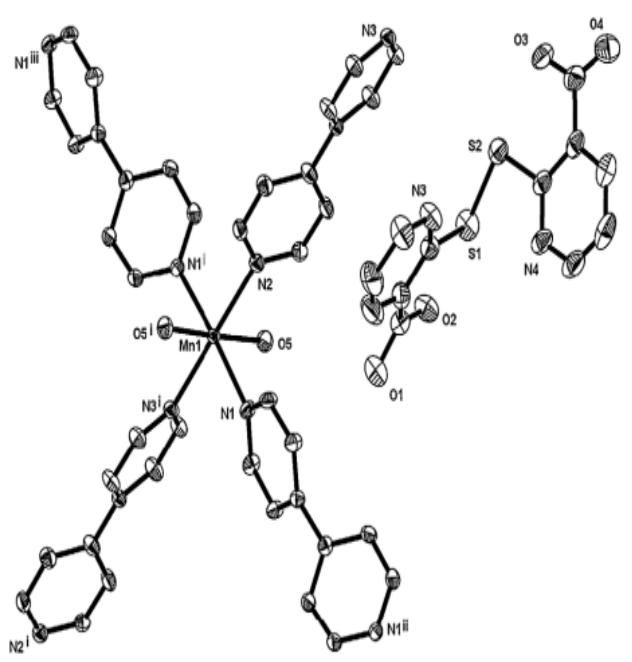

(c)

Fig. 15: $\mathrm{A}$ view of the coordination environment of the $\mathrm{Mn}$ atoms in $\left[\mathrm{Mn}\left(\mathrm{L}^{2}\right)(\mathrm{phen})\left(\mathrm{H}_{2} \mathrm{O}\right)\right]_{n} \mathrm{nH}_{2} \mathrm{O}(\mathrm{a}),\left[\mathrm{Mn}\left(\mathrm{L}^{2}\right)(2,20-\right.$ bipy) $\left.\left(\mathrm{H}_{2} \mathrm{O}\right)\right] \mathrm{n} .2 \mathrm{nH}_{2} \mathrm{O}$ (b) and $\left[\mathrm{Mn}\left(4,4_{0} \text {-bipy }\right)_{2}\left(\mathrm{H}_{2} \mathrm{O}\right)_{2}\right] \mathrm{n} 2 \mathrm{~nL}^{3}$ (c)

Two complexes of seven $\mathrm{Mn}(\mathrm{II})$ coordinated complexes having formula $\left[\mathrm{Mn}(\mathrm{phen})(\mathrm{nicot})\left(\mathrm{NO}_{3}\right)\left(\mathrm{H}_{2} \mathrm{O}\right)\right] \mathrm{EtOHH}_{2} \mathrm{O}$ (1) and also $\left[\mathrm{Mn}(\right.$ phen $\left.)\left(\mathrm{NO}_{3}\right) 2\left(\mathrm{H}_{2} \mathrm{O}\right)\right]$ (2) were analyzed by XRD. Bidentate ligands such as 2, 9-dimethyl-1, 10phenanthroline, nitrato and nicotinato anions, having N-Mn distance connected with 2.21-2.3 $\AA$ and Mn-O miles of 2.17-2.40 А. In both complexes, the water molecule was apparently the strongest linkage with ligand, with

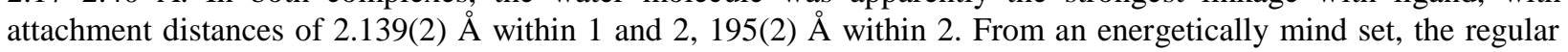
ratio between matched up uni-dentate and bidentate bond lengths under the unity justifies, the geometry connected with the coordination polyhedral. In the structure of 1 , the coordination polyhedron might be described its best as any distorted pentagonal bipyramid having a nitrogen from phenanthroline and also the molecule of water occupying the actual apical position. The shape for polyhedron 2 was near to a square-capped trigonal prism, the actual capping site getting occupied by the lake molecule. H-bonded bi-dimensional sheets piled up by $\mathrm{p}-\mathrm{p}$ stacking from the partially interpenetrated aromatic moieties of adjoining layers designed the structure of the crystal [7].

\section{$\mathrm{Mn}^{+2}$ complexes with imidazole:-}

It was stated that complexes of $\mathrm{Mn}$ with imidazole were prepared like imidazole manganese (II) terephthalate $\left(\left[\mathrm{Mn}(\mathrm{Imi})_{6}\right](\text { teph })_{4} \mathrm{H}_{2} \mathrm{O}\right)$ where: Imi: imidazole and their interaction with DNA was explained by FT-IR and cyclic voltammetry. Addition of DNA showed an increased fluorescence for $\left[\mathrm{Mn}(\operatorname{Imi})_{6}\right]^{2+}$. When $\left[\mathrm{Mn}(\operatorname{Imi})_{6}\right]^{2+}$ was added, fluorescence phenomenon shown for EB-DNA system. The cyclic voltammogram on the glassy carbon electrode were used to show peaks of a couple quasi-reversible of $\left[\mathrm{Mn}(\mathrm{Imi})_{6}\right]^{2+}$. The positive shift of the formal potential decreased the $\left[\mathrm{Mn}(\mathrm{Imi})_{6}\right]^{2+}$ peak current in the presence of DNA instead of its absence. Intercalative binding mode was used to bind $\left[\mathrm{Mn}(\operatorname{Imi})_{6}\right]^{2+}$ and DNA. For DNA- $\left[\mathrm{Mn}(\operatorname{Imi})_{6}\right]^{2+}$ association complex, 1:1and 4.44 was binding ratio and binding constant respectively (Shu et al.,2005).The geometry-based aromaticity indexes for benzoates metal, salicylates, nicotinates and derivatives of benzene were calculated. They studied the stabilizing metals effect on the system of p-electron s. The given and previous spectroscopic results were analyzed and statistically analyzed and their applications of the indexes were discussed. The highest degree of electronic charge distribution was in following elements: $\mathrm{Al}, \mathrm{Cr}, \mathrm{Mg}, \mathrm{Ni}$ and $\mathrm{Zn}[8]$

It was given that an acetamide complex was synthesized which holds two terminal imidazole rings. Biomimetic ligand of this type, $\mathrm{N}$-[2-(1H-imi-4-yl)-ethyl]-2-([2-(1H-imil-4-yl)-ethylcarbamoyl]-methyl -amino)-acetamide, had been in addition covered with silica exterior through covalent bonding. You're backed in addition to non-supportive bio mimetics showed reaction along with manganese (II) ions producing the development in the matching material things. These types are already examined since catalysts pertaining to alkene epoxidation along with $\mathrm{H}_{2} \mathrm{O}_{2}$ within the profile of ammonium acetate since the item. Our own information confirmed how the homogeneous and the backed methods can easily get over the reasonably competitive $\mathrm{H}_{2} \mathrm{O}_{2}$ dis-mutation, using only two fold $\mathrm{H}_{2} \mathrm{O}_{2}$ regarding substrate, favoring fruitful alkene epoxidations to some important magnitude [43]. A novel molybdenum arsenate 
compound $\left[\left\{\mathrm{Cu}(\mathrm{imi})_{2}\right\}_{3} \mathrm{As}_{3} \mathrm{Mo}_{3} \mathrm{O}_{15}\right] \mathrm{H}_{2} \mathrm{O}$ (imi = imidazole) 1 , has been prepared by hydrothermal method and structurally characterized by elemental analysis, IR, XPS, TG analysis and single-crystal X-ray diffraction analysis. Compound 1 represents the first example of molybdenum arsenate fragment $\left[\mathrm{As}_{3} \mathrm{Mo}_{3} \mathrm{O}_{15}\right] 3$ as polydentate ligand covalently bonded to three ${ }^{1 / 2} \mathrm{CuI}$ ðimip2 complexes through $\mathrm{O}_{\mathrm{b}} \ldots \mathrm{O}_{\mathrm{t}, \ldots}, \mathrm{O}_{\mathrm{b}}\left(\mathrm{O}_{\mathrm{t}}\right.$, terminal oxygen; $\mathrm{O}_{\mathrm{b}}$, bridging oxygen $)$ atoms. The electrochemical behavior and electro-catalysis of 1-modified carbon paste electrode (CPE) have been studied in detail [44].

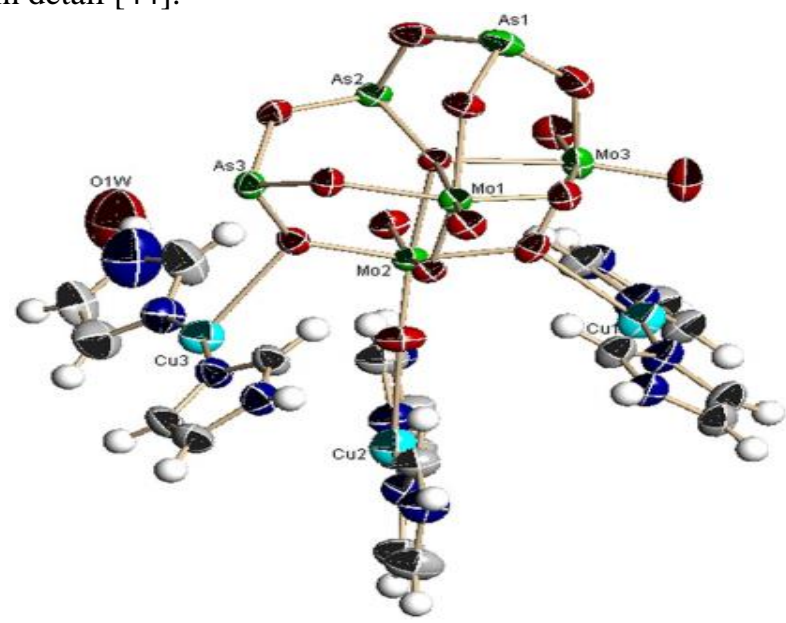

(a)

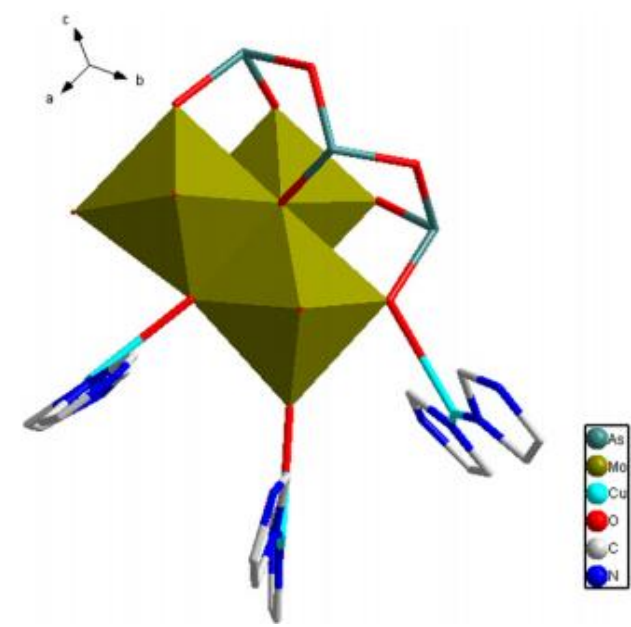

(b)

Fig. 16:ORTEP drawing (a) and view of the coordination environment (b) of $\left[\left\{\mathrm{Cu}(\mathrm{imi})_{2}\right\}_{3} \mathrm{As}_{3} \mathrm{Mo}_{3} \mathrm{O}_{15}\right] \mathrm{H}_{2} \mathrm{O}$ $(\mathrm{imi}=$ imidazole $)$

It was stated that a Schiff base ligand (3-aminopropyl) imidazole along with salicylaldehyde that coordinate with $\mathrm{Zn}(\mathrm{II}), \mathrm{Cu}(\mathrm{II})$ and $\mathrm{Ag}(\mathrm{I})$ center and their X-ray crystal structure of these complexes were obtained. In vivo most of the complexes and all ligands were inactive toward Galleria mellonella. It vitro $\mathrm{Cu}(\mathrm{II}), \mathrm{Zn}$ (II) complexes were inactive while $\mathrm{Ag}(\mathrm{I})$ complex show some extent of anti-microbial activity and good fungal activity[45].

Many imidazole-dioxolane complexes were being prepared and assessed as novel inhibitors regarding heme oxygenase (HO). These complexes, that included a series of thiophenol substituted and also phenol substituted derivatives regarding $\quad(2 \mathrm{R}, \quad 4 \mathrm{~S})-2$-[2-(4-chlorophenyl)ethyl]-2-[(1H-imidazol-1-yl)methyl]-4[(phenylsulfanyl)methyl]-1, 3-dioxolane hydrochloride (3), besides small functionalized derivatives, continued our structural-activity studies by exploring with the amino thiophenol area ('northeastern region') in your original target construction azalanstat (1). Inside vitro, most with the complexes in this series were found to be inhibitors that were highly potent with the stress-induced isozyme HO-1 and the constitutive isozyme HO-2, demonstrating only optimum selectivity with regard to HO-1. Nevertheless, some of the complexes showed larger selectivity toward HO-1. None with the complexes having a larger appendage in the northeastern region were being inhibitors of CYP2E1, whereas a compound using relatively small substituent fluorine in this region did blocked CYP2E1; each of the complex tested showed very high inhibitory effectiveness towards CYP3A1/3A2 [46]. Two new coordination complexes, $\left[\mathrm{Zn}_{2}(\mathrm{PIDC})\left(\mathrm{H}_{2} \mathrm{O}\right) \mathrm{Cl}\right] \mathrm{n}$ (a) and $\left\{\left[\mathrm{Mn}(\mathrm{HPIDC}) \mathrm{H}_{2} \mathrm{O}\right] 2 \mathrm{H}_{2} \mathrm{O}\right\} \mathrm{n}(\mathrm{b})$, were synthesized hydrothermally by reacting $\mathrm{Mn}$ (II)salt that has a strong 1, 4-bis(1-imidazol-yl)-2,5-dimethyl benzene and different carboxylate ligands. Intricate a was some sort of binodal $(3,7)$ associated 3-D structure with point symbolic representation (44. 617). (63). Complex b was usually a $(3,6)$ associated 3-D composition with symbolic representation (3. 4. 5). (32. forty two. 5. 63. 72). the actual luminescent properties of $\mathrm{a}$ and $\mathrm{b}$ were investigated from the solid state at room temperature [47]. 


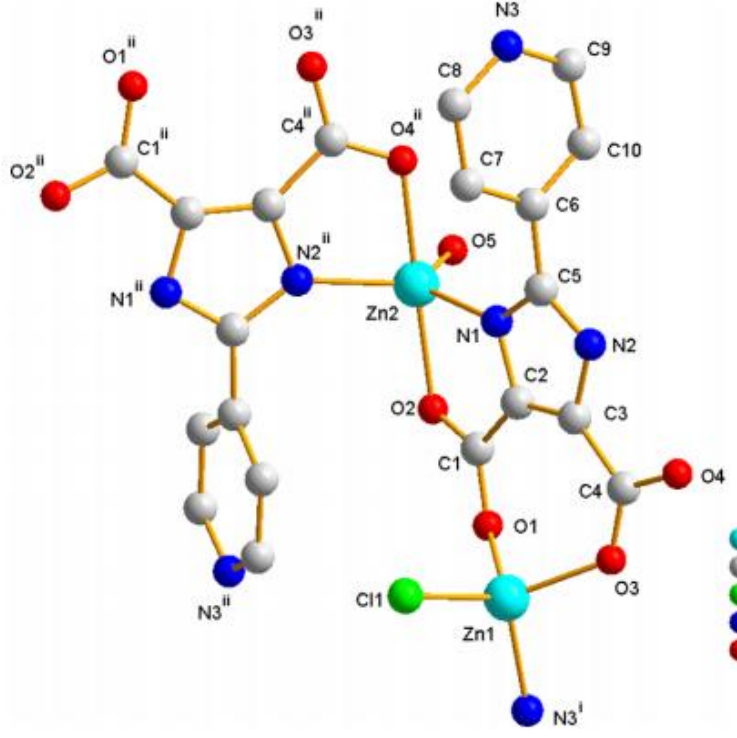

(a)

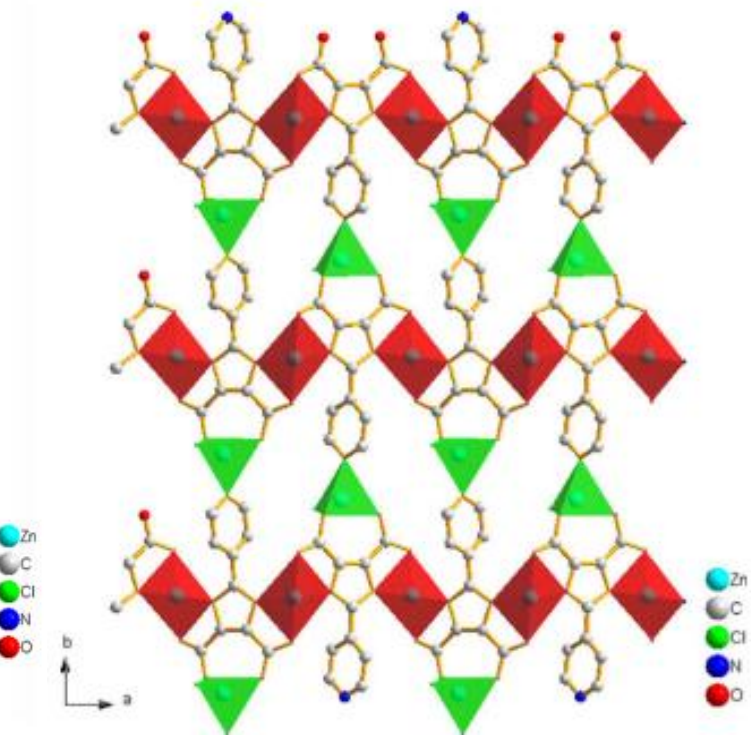

(b)

Fig. 17:-View of the coordination environment of $\mathrm{Zn}$ in $\left[\mathrm{Zn}_{2}(\mathrm{PIDC})\left(\mathrm{H}_{2} \mathrm{O}\right) \mathrm{Cl}\right] \mathrm{n}$ complex (a), A two-dimensional network structure for $\left[\mathrm{Zn}_{2}(\mathrm{PIDC})\left(\mathrm{H}_{2} \mathrm{O}\right) \mathrm{Cl}\right] \mathrm{n}$ complex

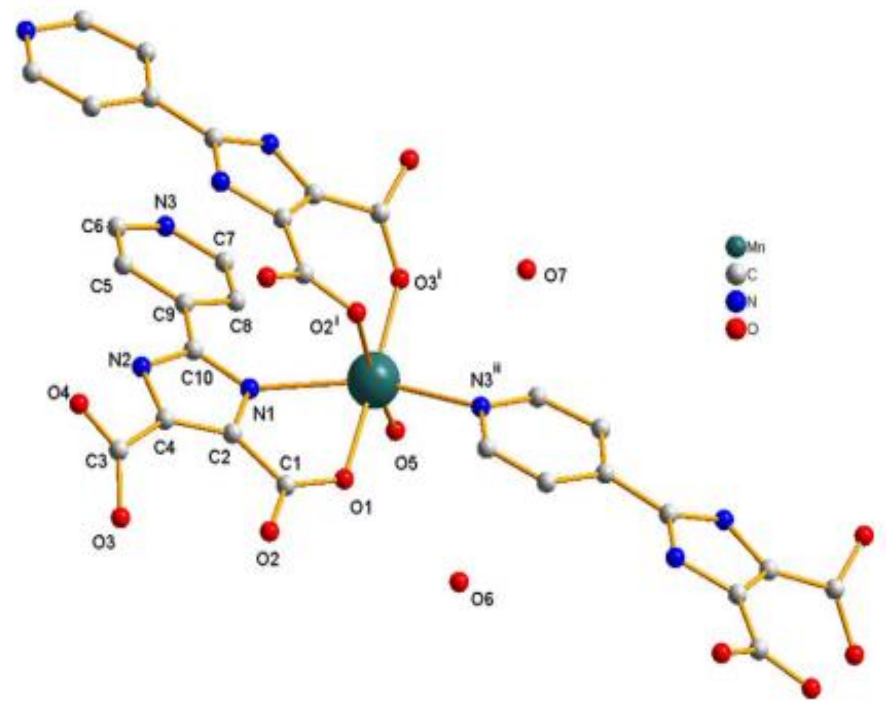

Fig. 18:-View of the coordination environment of $\mathrm{Mn}$ in $\left\{\left[\mathrm{Mn}(\mathrm{HPIDC}) \mathrm{H}_{2} \mathrm{O}\right] 2 \mathrm{H}_{2} \mathrm{O}\right\} n$

It was stated that complexes of Z-2-benzyltbio-4-hydroximinomethyl-1-p-methoxyphenyl imidazole (Z-OXLME) along with Co", Ni", Cui', Zn", Cd" and Hg" were synthesized and characterized simply by IR, W-vis-NIR reflectance, ' $\mathrm{H}$ and 13C NMR spectroscopic methods and magnetic and winter calculations. In all of the compounds the organic and natural complexes act as a chelates through N(3) imida and Noximea toms [48].

Barszcz et al. (1999) [49] synthesized and characterized two different coordinate compounds of $\mathrm{Cu}$ (II) by using bidentate ligands like 1-benzyl-2-hydroxymethylimidazole, 4-methyl and 5-imidazole. $\left[\mathrm{Cu}\left(1-\mathrm{Bz}-2-\mathrm{CH}_{2} \mathrm{OHIm}\right)_{4}\right.$ ]$\left(\mathrm{NO}_{3}\right)_{2}$ and also $\left[\mathrm{Cu}(4-\mathrm{Me}-5-\mathrm{CHOIm})_{4}\right]\left(\mathrm{H}_{2} \mathrm{O}\right)_{2} \quad\left(\mathrm{NO}_{3}\right)_{2}$ complexes single crystal were used for structure determination. The structural data for first coordination compound show $\mathrm{Cu}(\mathrm{II})$ ion were involved in the tetrahedron of $\mathrm{N}(1,2,3,4)$ atoms of imidazole ring along with four of $\mathrm{z}$-axis oxygen atoms tetrahedron of aldehyde groups. The six coordinated $\mathrm{Cu}$ (II) complex have a distorted tetragonal pyramidal geometry. Other techniques used for detection and characterization of coordination mode of copper in solution phase were electron paramagnetic resource (EPR) and UV-Vis. Hexakis (N-methyl imidazole) copper salicylate were prepared by the reaction of copper aspirinate 
with N-Methyl imidazole. This coordination complex characterized by crystallographic and spectroscopic method. By applying xanthine-xanthine oxidase assay, SOD (superoxide dismutase activity) of the complex was determined [50].

Processes were explained for that preparation carboxylate complex of manganese that was tetra-nuclear with ligands produced from4-imidazoleacetic acid (imidacH) along with 4-imidazolecarboxylic acid (imidcarbH). Problem containing mixtures NBun4 imidac or even NHexn4 imidcarb made in situ along with either $\left[\mathrm{Mn}_{3} \mathrm{O}\left(\mathrm{O}_{2} \mathrm{CMe}\right)_{6}(\mathrm{py})_{3}\right]\left(\mathrm{ClO}_{4}\right)$ or even $\mathrm{Mn}\left(\mathrm{O}_{2} \mathrm{CR}\right)_{2}, \mathrm{RCO}_{2} \mathrm{H}(\mathrm{R}=\mathrm{Me}, \mathrm{Ph})$ along with $\mathrm{NR} \% 4 \mathrm{MnO}_{4}(\mathrm{R} \%$ _Bun, Hexn) gave red to brown solutions from where the products (NBun4) $\left[\mathrm{Mn}_{4} \mathrm{O}_{2}\left(\mathrm{O}_{2} \mathrm{CR}\right)_{7}(\mathrm{imidac})_{2}\right]\left(\mathrm{R} \_\mathrm{Me}(1) ; \mathrm{R} \_\mathrm{Ph}(2)\right.$ along with $\left.\left(\mathrm{NHexn}_{4}\right)\left[\mathrm{Mn}_{4} \mathrm{O}_{2}\left(\mathrm{O}_{2} \mathrm{CR}\right)_{7} \text { (imidcarb) }\right)_{2}\right](\mathrm{R}=\mathrm{Me}(3) ; \mathrm{R}=\mathrm{Ph}$ (4) could be formed. The structure 2 of $\mathrm{X}$-ray revealed that the anion containing an $\left[\mathrm{Mn}_{4}\left(\mathrm{~m}_{3}-\mathrm{O}\right)_{2}\right]_{8}$ core while using four atoms of Mn showed in a very 'butterfly' arrangement and also the atoms of $\mathrm{O}$ triply connecting each 'wing'. Peripheral ligation is furnished by seven bridging $\mathrm{O}_{2} \mathrm{CPh}$ - ligands along with two chelating imi organizations. All given data of characterization were in keeping with the same central for complexes 1, 3 along with 4, along with the buildings that differed only inside terminal ligation. 1H NMR spectroscopy of four complexes indicates that the structure was looked after in solution and a lot of the resonating structures have been given based on T1 measurements along with substitution and swap practical. Cyclic voltammetry showed the existence of the single quasi-reversible oxidation functions for complexes 1 along with 2 [51].

A couple of novel coordination polymers that were non-centrosymmetric, $\left[\mathrm{Zn}_{2}(\mathrm{PIDC})\left(\mathrm{H}_{2} \mathrm{O}\right) \mathrm{Cl}\right] \mathrm{n}$ (1) and $\left\{\left[\mathrm{Mn}(\mathrm{HPIDC}) \mathrm{H}_{2} \mathrm{O}\right]-2 \mathrm{H}_{2} \mathrm{O}\right\} \mathrm{n}(2)$ had been prepared by hydrothermal method and seen as a IR, elemental research and XRD technique. Complex 1 crystallized in a chiral space classP212121 has a 2D network design. Complex 2 was really a 3D open composition with $1 \mathrm{D}$ station where $1 \mathrm{D}$ zigzag water chains tend to be residue by hydrogenbonding friendships and chiral space crystallization in class Cc. Both 1 as well as 2 showed a solid harmonic creation (SHG) response [52]. By using Schiff bases, compounds of $\mathrm{Zn}(\mathrm{II}), \mathrm{Mn}(\mathrm{II})$ and Fe(III) produced by amino based mercapto triazole. The magnetic, elemental and spectroscopic studies showed that metal complexes occupied an octahedral pattern (geometry). The Schiff bases along with their metal complexes explained fluorescent properties. An antibacterial scientific investigation of Schiff facets along their metallic compounds towards various bacteria (E.coli, S. aureus, Pseudomonas aeruginosa and B. subtilis) along with fungal (A. niger, and P. chrysogenum) species through slow inhibitory focus method showed that metal compounds own more of the healing antimicrobial phenomenon as compare to Schiff bases. Deoxy ribonuclease (DNA) cleavage plays an important role with $\mathrm{Mn}$ (II), Fe(III) and $\mathrm{Zn}(\mathrm{II})$ complexes in the concern biological system [53].

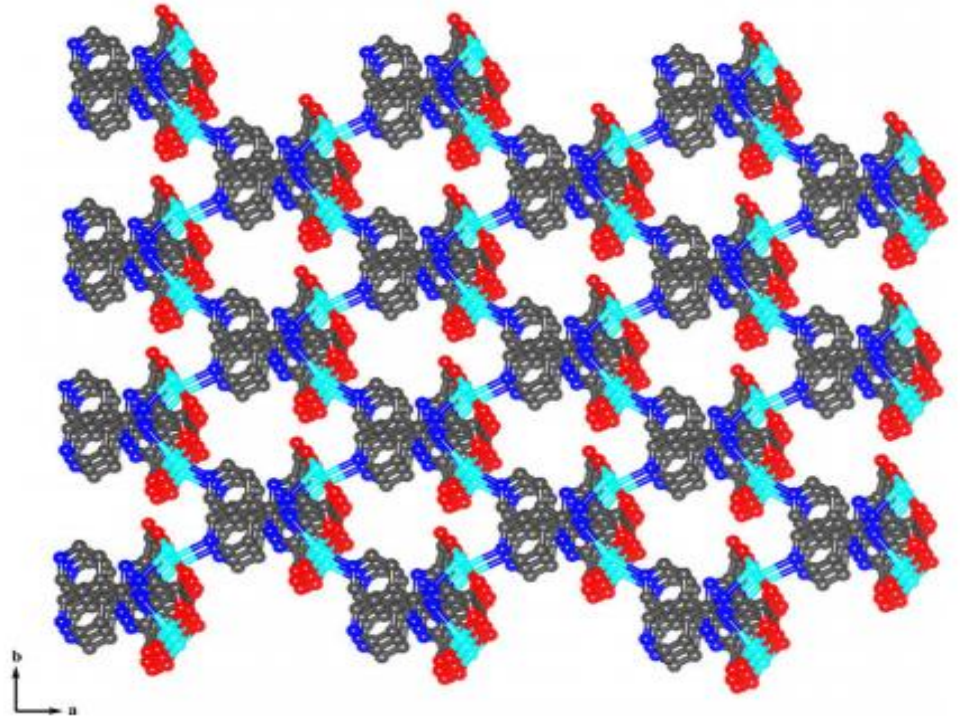

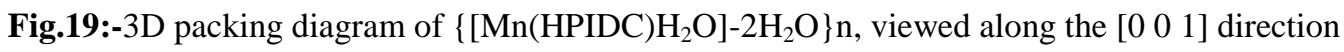

\section{Conclusion:-}

On the basis of various literature survey imidazole and nicotinic acid complexes of $\mathrm{Cu}$ (II) and Mn(II) show various activity against antimicrobial, anti-inflammatory, analgesic, anti-tubercular, anticancer etc. The possible 
improvements in the activity can be further achieved by slight modifications in the substituents on the basic imidazole and nicotinic acid nucleus. Thus imidazole and nicotinic acid complexes of $\mathrm{Cu}(\mathrm{II})$ and $\mathrm{Mn}$ (II) offers better pharmacodynamic characteristics. Furthermore, some imidazole drugs, at high concentrations, could exert direct inhibitory effects on membranes, without interference with sterols and sterol esters. Various recent new drugs developments in imidazole and nicotinic acid complexes of $\mathrm{Cu}(\mathrm{II})$ and $\mathrm{Mn}$ (II) show better effect and less toxicity.

\section{References:-}

1. Abuskhuna,S., McCann,M.,Briody,J., Devereux,M, and McKee,V.(2004): Synthesis and structure of Mn (II), $\mathrm{Cu}$ (II) and Zn (II) complexes containing bis-imidazole ligands. Polyhedron, 23: 1731-1737.

2. Al-Saif, F.A., and M.S. Refat, (2012): Ten metal complexes of vitamin b 3/niacin: Spectroscopic, thermal, antibacterial, antifungal, cytotoxicity and antitumor studies of $\mathrm{Mn}$ (II), Fe (III), Co (II), Ni (II), Cu (II), Zn (II), Pd (II), Cd (II), Pt (IV) and Au (III) complexes. J. Mol. Str., 1021: 40-52.

3. Brewer, G.C., Brewer, Butcher R.J., and CarpenterE.E., (2006): Synthesis and characterization of $\mathrm{Cu}(\mathrm{II})$ and $\mathrm{Ni}(\mathrm{II})$ complexes of a tripodal ligand containing imidazoles. Inorganica chimica acta, 359: 1263-1268.

4. Lide, D.R., (2004): Crc handbook of chemistry and physics. CRC press.

5. An, J., Chen, Z.D. Bian, J. Jin,X.L., Wang, S.X., and Xu, G.X. (1999): Synthesis, crystal structures and magnetic properties of trinuclear oxo-centered manganese complexes of the general formula [mn 3 o (o $2 \mathrm{cr}$ ) 61 3] $\mathrm{z}+(\mathrm{r}=\mathrm{me}$, et, ph, ch $2 \mathrm{cl} ; \mathrm{l}=3$-methylpyridine or water $\mathrm{z}=1,0)$. Inorganica chimica acta, 287: 82-88.

6. Boskovic, C.,Folting K., and Christou, G. (2000): Tetranuclear manganese carboxylate clusters with imidazolecarboxylate chelating ligands. X-ray crystal structure of the 4-imidazoleacetate complex. Polyhedron, 19: 21112118.

7. El-Azzouzi, N.F. Hueso-Ureña, N.A. Illán-Cabeza and M.N. Moreno-Carretero, (2010): Xrd structure of two heptacoordinated Mn (II) complexes containing 2, 9-dimethyl-1, 10-phenanthroline (phen), nitrato and nicotinato bidentate anions:[mn (phen)(nicot)(no 3)(h 2 o)] etoh. $\mathrm{H}_{2} \mathrm{O}$ and [mn (phen)(no 3) $\left.2\left(\mathrm{H}_{2} \mathrm{O}\right)\right]$. Polyhedron, 29: 1405-1410.

8. Zhang, S.S.S.Y., Niu, B. Qu, G. F. Jie, H. Xu and C.-F. Ding, (2005): Studies on the interaction mechanism between hexakis (imidazole) manganese (II) terephthalate and DNA and preparation of DNA electrochemical sensor. J. Inorg. Biochem., 99: 2340-2347.

9. Shalini K, Sharma PK, Kumar N. (2010): Imidazole and its biological activities: A review. Der Chemica Sinica, 1(3):36-47.

10. Keene, D., C. Price, M.J. Shun-Shin and D.P. Francis (2014): Effect on cardiovascular risk of high density lipoprotein targeted drug treatments niacin, fibrates, and cetp inhibitors: Meta-analysis of randomised controlled trials including 117411 patients. Bmj, 349: g4379, 1-13.

11. Perrone, D., Farah, A., Donangelo, C.M., de-Paulis, T., and Martin, P.R. (2008): Comprehensive analysis of major and minor chlorogenic acids and lactones in economically relevant Brazilian coffee cultivars. Food Chem., 106: 859-867.

12. Karter, A.J., Parker, M.M., Moffet, H.H., Spence, M.M., Chan, J., Ettner, S.L., Selby, J.V. (2006): Longitudinal study of new and prevalent use of self-monitoring of blood glucose. Diabetes care. 29(8):1757-1763.

13. Suksrichavalit T., Prachayasittikul S., Piacham T., Isarankura-Na-Ayudhya C., Nantasenamat C., and Prachayasittikul V. (2008): Copper complexes of nicotinic-aromatic carboxylic acids as superoxide dismutase mimetics. Molecules. 13(12):3040-3056.

14. Do Nascimento, A.L.C.S., Caires, F.J.,Gomes, D.J.C.,Gigante, A.C., and IonashiroM. (2014): Thermal behaviour of nicotinic acid, sodium nicotinate and its compounds with some bivalent transition metal ions. Thermochimica Acta, 575: 212-218.

15. Salama, R.H., Nassar, A.Y., Nafady, A.A., Mohamed H.H. (2007): A novel therapeutic drug (copper nicotinic acid complex) for non-alcoholic fatty liver. Liver international. 27(4):454-464.

16. Abuskhuna, S., McCann, M., Briody, J., Devereux, M., McKee, V. (2004): Synthesis and structure of Mn (II), $\mathrm{Cu}$ (II) and Zn (II) complexes containing bis-imidazole ligands. Polyhedron. 23(10):1731-1737.

17. Zhao, X.Q., Zhao, B., Ma, Y., Shi, W., Cheng, P., Jiang, Z.H., Liao, D.Z., Yan, S.P. (2007): Lanthanide (III)-Cobalt (II) Heterometallic Coordination Polymers with Radical Adsorption Properties. Inorganic chemistry. 46(15):5832-5834.

18. McGinley, J., M. McCann, K. Ni, T. Tallon, K. Kavanagh, M. Devereux, X. Ma and V. McKee, (2013). Imidazole schiff base ligands: Synthesis, coordination complexes and biological activities. Polyhedron, 55: 169178. 
19. Mizoguchi, T.J., Davydov, R.M., Lippard, S.J. (1999): Structural and spectroscopic comparisons between ( $\mu-$ oxo)-and ( $\mu$-hydroxo) bis ( $\mu$-carboxylato) diiron (III) complexes that contain all-oxygen-donor ligands. Inorganic Chemistry. 38(18):4098-4103.

20. Wang, Y.Y., Shi, Q.,Shi, Q.Z., Gao,Y.C., and Zhou, Z.Y. (1999): Syntheses, characterization and crystal structure of copper (ii) $\alpha, \beta$-unsaturated carboxylate complexes with imidazole. Polyhedron, 18: 2009-2015.

21. Sorrell, T.N., Garrity, M.L., Richards, J.L., White, P.S. (1994) Synthesis, structural characterization and dioxygen reactivity of imidazole-ligated $\mathrm{Cu}$ (I) complexes. Inorganica chimica acta. 218(1-2):103-108.

22. Hijleh, A.L. (1989): Synthesis and characterization of mononuclear copper (II) aspirinate adducts with imidazole and its methyl derivatives. Polyhedron. 8(23):2777-2783.

23. Carranza, J., Sletten, J., Lloret F., and Julve, M.(2009): Preparation, crystal structures and magnetic properties of three thiocyanato-bridged copper (ii) complexes with 2, 2'-biimidazole or 2-(2'-pyridyl) imidazole as terminal ligands. Polyhedron, 28: 2249-2257.

24. Luneau, D., and Rey, P. (2005): Magnetism of metal-nitroxide compounds involving bis-chelating imidazole and benzimidazole substituted nitronyl nitroxide free radicals. Coordination chemistry reviews, 249: 2591-2611.

25. Sunatsuki, Y., Motoda,Y.,and Matsumoto, N. (2002): Copper (II) complexes with multidentate schiff-base ligands containing imidazole groups: Ligand-complex or self-complementary molecule? Coordination chemistry reviews, 226: 199-209.

26. Soayed, A.A., Refaat,H.M.,and El-Din, D.A.N.,(2014): Characterization and biological activity of pefloxacinimidazole mixed ligands complexes. Inorganica Chimica Acta, 421: 59-66.

27. Xu, N., Wang, C., Cheng P., and Liao, D.Z.(2012): Ferro-/antiferromagnetic interactions in two onedimensional $\mathrm{Cu}(\mathrm{II})$ complexes: Syntheses, crystal structures and magnetic studies. Inorganic Chemistry Communications, 23: 85-89.

28. Guo, D.S. and Liu, Y. (2007): A novel supramolecular assembly constructed by cu/imidazole complex with 1, 2-alternate p-sulfonatothiacalix [4] arene. Crystal growth \& design, 7: 1038-1041.

29. Patil, S.A., Manjunatha, M., Kulkarni,A.D.,and Badami, P.S. (2014). Synthesis, characterization, fluorescence and biological studies of $\mathrm{Mn}(\mathrm{II})$, Fe(III) and $\mathrm{Zn}$ (II) complexes of schiff bases derived from isatin and 3substituted-4-amino-5-mercapto-1, 2, 4-triazoles. Complex Metals, 1: 128-137.

30. Carballo, R., Castineiras, A. Covelo, B. Garcı-Martınez, E. Niclós J. and Vázquez-López, E. (2004). Solid state coordination chemistry of mononuclear mixed-ligand complexes of $\mathrm{Ni}(\mathrm{II}), \mathrm{Cu}(\mathrm{II})$ and $\mathrm{Zn}$ (II) with $\alpha$ hydroxycarboxylic acids and imidazole. Polyhedron, 23: 1505-1518.

31. Song, J.F., Chen, Y.,Li, Z.G.,Zhou,R.S., Xu,X.Y., and Xu, J.Q. (2007): Copper and cobalt coordination polymers based on isophthalate as bridging ligands and imidazole as capping ligands: Syntheses, crystal structures, spectroscopic characterization. Journal of Molecular Structure, 842: 125-131.

32. Caswell, D.S., and T.G. Spiro, (1986): Ultraviolet resonance raman spectroscopy of imidazole, histidine, and cu (imidazole) 42+: Implications for protein studies. Journal of the American Chemical Society, 108: 6470-6477.

33. Valderrama-Negrón, A.C., Alves, W.A.,Cruz, Á.S.,Rogero,S.O.,and de Oliveira Silva, D.,(2011): Synthesis, spectroscopic characterization and radiosensitizing properties of acetato-bridged copper (ii) complexes with 5nitroimidazole drugs. Inorganica Chimica Acta, 367: 85-92.

34. Gogoi, A., Sarmah, G.,Dewan A., and Bora, U.(2014): Unique copper-salen complex: An efficient catalyst for n-arylations of anilines and imidazoles at room temperature. Tetrahedron Letters, 55: 31-35.

35. Galić, N., Rubcic, M., Magdic,K., Cindric,M., and Tomisic, V.(2011): Solution and solid-state studies of complexation of transition-metal cations and $\mathrm{Al}$ (III) by aroylhydrazones derived from nicotinic acid hydrazide. Inorganica chimica acta, 366: 98-104.

36. Jiao, Y.K., Li, X.P.,Zhao, C.,Wang, H.C.,Xue, M.,Zhao,J.P.,and Liu, F.C. (2013): Novel heterometallic metalazido complex synthesized by "one-step" reaction: Synthetic strategy and magnetic properties. Journal of Solid State Chemistry, 202: 257-261.

37. Sanchirico, R., Russo, P., Saliva, A., Doussot, A., Di-Sarli, V., Di-Benedetto, A. (2015):Explosion of lycopodium-nicotinic acid-methane complex hybrid mixtures. Journal of Loss prevention in the process industries. 36:505-508.

38. Can, N., Can, S.S.,Atac,A., and Bardak, F. (2004): Structural characterization and luminescence properties of an isonicotinic acid n-oxideMn (II) complex. Polyhedron, 23: 1109-1113.

39. Yang, Q., Zhao,J.P., Hu, B.W.,Zhang,X.F., and Bu, X.H.,(2010): New manganese (ii) azido coordination polymers with nicotinic/isonicotinic acids as coligands: Synthesis, structure, and magnetic properties. Inorganic chemistry, 49: 3746-3751. 
40. Yang, L., Liu, L., Wu, L., Xu Z., and Wang, L.(2014): Isomorphous and isostructural lanthanide coordination polymers based on 2-(4-chlorobenzoyl) benzoic acid: Synthesis, structure, characterization, and luminescent properties. Dyes and Pigments, 111: 176-184.

41. Liu, F.C., Zeng, Y.F.,Li, J.R., Bu, X.H.,Zhang,H.J.,and Ribas, J. (2005): Novel 3-d framework Nickel (II) complex with azide, nicotinic acid, and nicotinate (1-) as coligands: Hydrothermal synthesis, structure, and magnetic properties. Inorganic chemistry, 44: 7298-7300.

42. Xiao, H.P., Liu, B.L.,Liang, X.Q., Zuo,J.L., and You, X.Z.,(2008): Synthesis and crystal structures of manganese (II) complexes with the ligands from in situ oxidation of 2-mercaptonanicotinic acid. Inorganic Chemistry Communications, 11: 39-43.

43. Serafimidou, A., Stamatis,A., and Louloudi,M., (2008): Manganese (II) complexes of imidazole basedacetamide as homogeneous and heterogenised catalysts for alkene epoxidation with $\mathrm{H} 2 \mathrm{O} 2$. Catalysis Communications, 9: 35-39.

44. Zhao, Z., Zhou,B., Su, Z., Ma H., and Li, C.(2008): A new [As3Mo3O15] 3- fragment decorated with cu (I)imi (imi= imidazole) complexes: Synthesis, structure and electrochemical properties. Inorganic Chemistry Communications, 11: 648-651.

45. McGinley, J., McCann, M.,Ni, K.,Tallon, T.,Kavanagh, K.,Devereux, M., Ma,X.,and McKee,V.(2014): Imidazole schiff base ligands: Synthesis, coordination complexes and biological activities. Polyhedron, 56: 190198.

46. Vlahakis, J.Z., Hum, M.,Rahman, M.N.,Jia, Z.,Nakatsu,K., and Szarek, W.A.,(2009): Synthesis and evaluation of imidazole-dioxolane compounds as selective heme oxygenase inhibitors: Effect of substituents at the 4position of the dioxolane ring. Bioorganic \& medicinal chemistry, 17: 2461-2475.

47. Chen, L.Z., Huang,Y., Xiong,R.G., and Hu, H.W.,(2010): Synthesis and structures of two novel noncentrosymmetric metal-organic polymers containing 2-(pyridin-4-yl)-1h-imidazole-4, 5-dicarboxylic acid ligands. Journal of Molecular Structure, 963: 16-21.

48. Lopez-Garzon, R., Moreno-Carretero, M.,Salas-Peregrin M.,and Salas-Peregrin, J. (1993): Synthesis and structural studies on z-2-benzylthio-4-hydroximinomethyl-1-p-methoxyphenyl imidazole metal complexes. Polyhedron, 12: 507-512.

49. Barszcz, B., Głowiak, T., Jezierska, J. (1999): Crystal and molecular structures of eight-coordinate (Cu N4O2) and six-coordinate (CuN4O2) $\mathrm{Cu}$ (II) complexes with 4-methyl-5-imidazole-carboxaldehyde or 1-benzyl-2hydroxymethylimidazole, respectively: spectroscopic and potentiometric studies. Polyhedron. 18(27):37133721.

50. Khalid, H., Hanif, M., Hashmi,A.M., Mahmood, T., Ayub, K., Monim-ul-Mehboob, M. (2013): Copper complexes of bioactive ligands with superoxide dismutase activity. Mini reviews in medicinal chemistry. 13(13):1944-1956.

51. Toma, H.E., Araki,K., and Dovidauskas, S.(2000): A cyclic voltammetry experiment illustrating redox potentials, equilibrium constants, and substitution reactions in coordination chemistry. Journal of Chemical Education, 77: 1351.

52. Chen, L.Z., Huang, Y., Xiong, R.G., Hu, H.W. (2011): Synthesis and structures of two novel noncentrosymmetric metal-organic polymers containing 2-(pyridin-4-yl)-1H-imidazole-4, 5-dicarboxylic acid ligands. Journal of Molecular Structure. 965(5):31-38.

53. Li, M., Gou, Y.,Yang,F., and Liang, H. (2014): DNA binding, cytotoxicity and apoptosis induction activity of a mixed-ligand $\mathrm{Mn}$ (II), Fe(III) and Zn(II) complexes with taurine schiff base and imidazole. Spectrochimica Acta Part A: Molecular and Biomolecular Spectroscopy, 128: 686-693. 